\title{
Albumin Nanoparticle Formulation for Heart-Targeted Drug Delivery: In Vivo Assessment of Congestive Heart Failure
}

\author{
Nikita Lomis ${ }^{1,2} \mathbb{D}$, Ziyab K. Sarfaraz ${ }^{3}$, Aiman Alruwaih ${ }^{3}$, Susan Westfall ${ }^{4}$, Dominique Shum-Tim ${ }^{3} \mathbb{D}$ and \\ Satya Prakash 1,2,* \\ 1 Department of Biomedical Engineering, Biomedical Technology and Cell Therapy Research Laboratory, \\ McGill University, 3775 University Street, Montreal, QC H3A 2B4, Canada; nikita.lomis@mail.mcgill.ca \\ 2 Division of Experimental Medicine, McGill University, 1001 Boulevard Décarie, \\ Montréal, QC H4A 3J1, Canada \\ 3 Division of Cardiac Surgery and Surgical Research, McGill University, 1001 Boulevard Décarie, \\ Montréal, QC H4A 3J1, Canada; Ziyab.Sarfaraz@mail.mcgill.ca (Z.K.S.); \\ Aiman.Alruwaih@mail.mcgill.ca (A.A.); Dominique.Shum-Tim@mcgill.ca (D.S.-T.) \\ 4 Meakins Christie Laboratories, Department of Microbiology and Immunology, McGill University, \\ 1001 Boulevard Décarie, Montréal, QC H4A 3J1, Canada; Susan.Westfall@mcgill.ca \\ * Correspondence: satya.prakash@mcgill.ca; Tel.: +1-514-398-2736
}

check for updates

Citation: Lomis, N.; Sarfaraz, Z.K.; Alruwaih, A.; Westfall, S.; Shum-Tim, D.; Prakash, S. Albumin Nanoparticle Formulation for Heart-Targeted Drug Delivery: In Vivo Assessment of Congestive Heart Failure. Pharmaceuticals 2021, 14, 697. https://doi.org/10.3390/ph14070697

Academic Editors: Kazuaki Taguchi and Victor Tuan Giam Chuang

Received: 10 June 2021

Accepted: 9 July 2021

Published: 19 July 2021

Publisher's Note: MDPI stays neutral with regard to jurisdictional claims in published maps and institutional affiliations.

Copyright: (c) 2021 by the authors. Licensee MDPI, Basel, Switzerland. This article is an open access article distributed under the terms and conditions of the Creative Commons Attribution (CC BY) license (https:// creativecommons.org/licenses/by/ $4.0 /)$.

\begin{abstract}
Congestive heart failure is a fatal cardiovascular disease resulting in tissue necrosis and loss of cardiac contractile function. Inotropic drugs such as milrinone are commonly used to improve the myocardial contractility and heart function. However, milrinone is associated with severe side effects and lower circulation time. In this article, a novel protein nanoparticle formulation for heart-targeted delivery of milrinone has been designed and tested. The formulation was prepared using albumin protein conjugated with the targeting ligand, angiotensin II peptide to form nanoparticles following the ethanol desolvation method. The formulation was characterized for size, charge, and morphology and tested in a rat model of congestive heart failure to study pharmacokinetics, biodistribution, and efficacy. The overall cardiac output parameters were evaluated comparing the formulation with the control non-targeted drug, milrinone lactate. This formulation exhibited improved pharmacokinetics with a mean retention time of $123.7 \mathrm{~min}$, half-life of $101.3 \mathrm{~min}$, and clearance rate of $0.24 \mathrm{~L} /\left(\mathrm{kg}^{*} \mathrm{~h}\right)$. The targeted formulation also significantly improved ejection fraction and fractional shortening parameters thus improving cardiac function. This study demonstrates a new approach in delivering inotropic drugs such as milrinone for superior treatment of congestive heart failure.
\end{abstract}

Keywords: albumin; nanoparticle; protein; milrinone; heart failure; drug delivery; pharmacokinetics; biodistribution

\section{Introduction}

Cardiovascular diseases are responsible for disability and mortality across the developed and developing world, of which congestive heart failure $(\mathrm{CHF})$ has ever-rising incidences [1]. The more commons treatments for CHF include surgical measures such as heart transplant, ventricular assist devices, bypass surgeries, and stents [2]. Medical treatments involve delivery of drugs such as inotropes, angiotensin-converting enzyme inhibitors, beta blockers, diuretics, etc. To improve the limitations associated with the use of non-targeted drugs, promising research has been undertaken especially in the field of nanomedicine $[3,4]$. The application of nanomedicine in cardiac therapy represents an innovative approach for efficient delivery of therapeutic agents such as drugs, genes, growth factors, cytokines, and other molecules [5-8]. However, despite the prominent advances on the use of nanoparticles as drug delivery systems for cancer therapy, fewer such studies have been reported in cardiovascular diseases, which claim millions of lives annually, also causing a huge economic burden $[9,10]$. Therefore, developing a targeted nanoparticle 
formulation would help overcome limitations associated with current pharmacological treatments and result in effective treatment of CHF [11].

Currently, the treatment of myocardial infarction (MI) and CHF involves administration of drugs either intravenously or orally in both adults and pediatric patients. However, lower retention times call for a continuous infusion of drugs with lack of target specificity, potentially causing toxicity and other side effects such as arrythmias, palpitations for off-target organs [12]. Though some studies using nanoparticles for growth factor delivery have suggested strong cardioprotective effects through direct myocardial injection, retaining the nanoparticles remains a challenge $[6,13,14]$. An ideal nanoparticle formulation would be biocompatible, biodegradable, possessing optimal particle size, surface charge, surface modifiable characteristics, targeting features, and longer blood circulation time. The nanoparticle system reported in this study, developed from human serum albumin (HSA-NPs) protein covers the above aspects and also binds the milrinone (MRN) drug molecule [10]. With an improved pharmacokinetics profile and drug delivery to the infarcted site, it enhances the therapeutic effect of the drug. Further, the controlled release of the MRN from the nanoparticles at the targeted site would allow for a single dose injection as opposed to a continuous supply. Being biodegradable, non-toxic, and non-immunogenic, HSA-NPs are a more favourable option than other carriers [15]. Several albumin-based nanocarriers have already been developed owing to their increased specificity, biocompatibility, and ability for surface functionalization $[5,16]$.

It is widely known that under MI and CHF, the angiotensin II type 1 (AT1) receptors are overexpressed on the myocardium. These receptors are specific for the angiotensin molecule, an 8-amino acid chain peptide (Asp-Arg-Val-Tyr-Ile-His-Pro-Phe) [17,18]. The overexpression of AT1 receptors has been correlated directly with cardiac remodelling due to HF, explaining the use of drugs to block these receptors [19]. Similarly, the downregulation of AT1R expression has shown significant improvement in cardiac function $[7,20]$. Emerging strategies on functionalized AT1 receptor-targeted nanoparticles such as liposomes, quantum dots, PLGA microcapsules as drug delivery systems present a creative and modern outlook on heart failure treatment $[8,16,19]$. Thus, the study of AT1 receptors as targets for the delivery and uptake of drugs, nanoparticles, and other biomolecules has immense potential for development for potent cardiac therapies.

In this study, we report the design and development of a targeted nanoparticle formulation for delivery of MRN to treat CHF. This formulation was prepared using HSA conjugated with the targeting ligand, AT1 peptide to form nanoparticles binding MRN. The AT1-HSA-MRN-NPs were characterized in vitro and tested in vivo. We studied the pharmacokinetic parameters of the AT1-HSA-MRN-NPs compared with the control nontargeted drug, MRN Lactate. Through a second in vivo study, the treatment efficacy of the AT1-HSA-MRN-NPs vs. MRN Lactate has been evaluated in a rat model of congestive heart failure.

\section{Results}

\subsection{Synthesis of AT1-HSA-MRN-NPS}

The AT1-HSA-MRN-NPs were developed for targeted delivery of MRN to the heart [10]. The overexpression of the AT1 receptors in cardiomyocytes allows for improved targeting of the AT1 peptide and hence greater uptake of the nanoparticle [21]. The AT1 peptide is an 8-amino acid peptide chain of Asp-Arg-Val-Tyr-Ile-His-Pro-Phe. On the N-terminal of the chain, 4 Gly residues were added to serve as a spacer to form $\mathrm{NH}_{2}$-Gly-Gly-Gly-Gly-AspArg-Val-Tyr-Ile-His-Pro-Phe- $\mathrm{NH}_{2}$ as given in a study by Dvir et al. [16]. The synthesis of the AT1-HSA was through a two-step chemical reaction using heterobifunctional cross-linkers. In the first step, the primary amines present on the surface of HSA molecules react with the amines on PA-(PEG) ${ }_{4}$-SPA. In the second step, EDC (pH 5.5) and Sulfo-NHS were added followed by addition of the AT1 peptide. The EDC reacts with the carboxyl group on one end and Sulfo-NHS reacts with amine present on the AT1 peptide, releasing the unstable intermediates and forming AT1-HSA (Figure 1). 


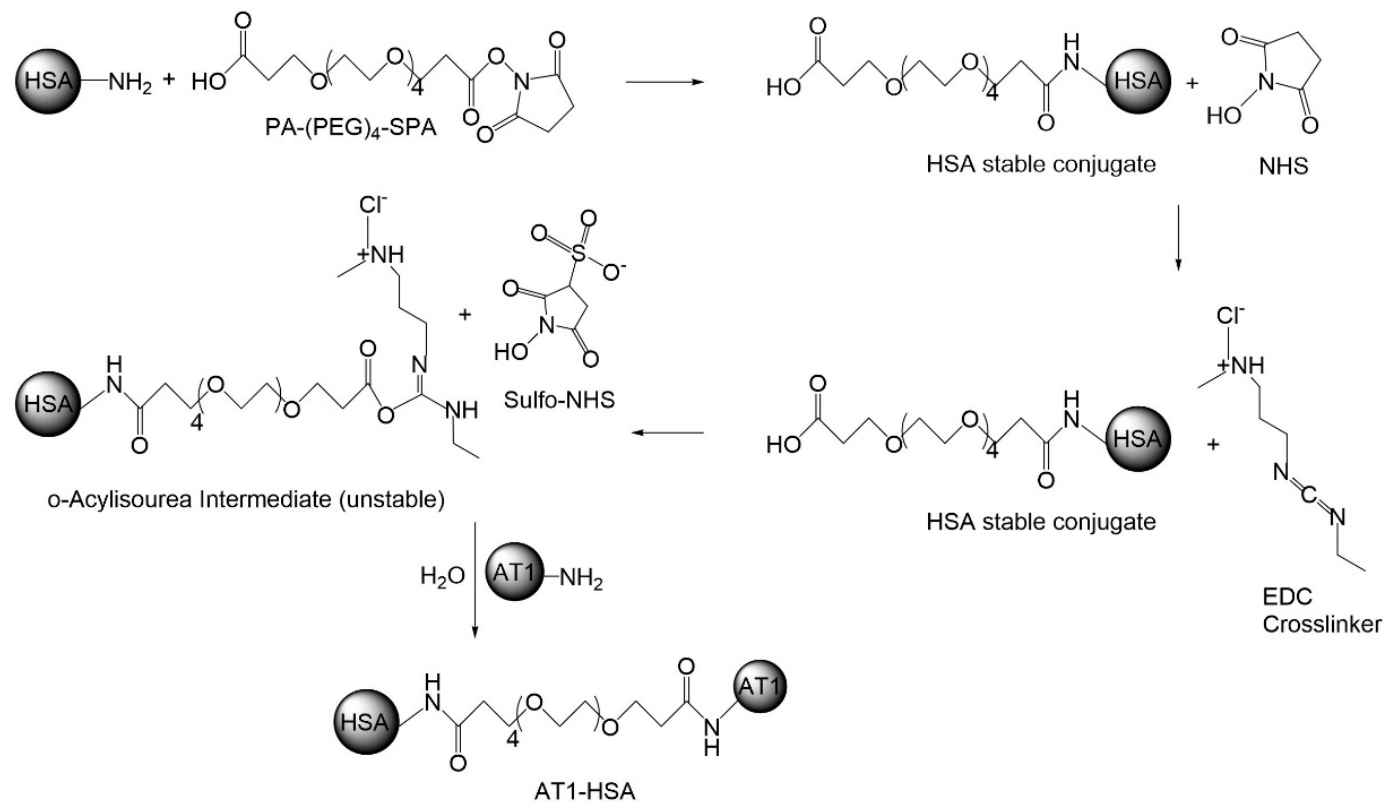

Figure 1. Schematic representation of the surface modification of the HSA molecule for binding with the AT1 peptide through a two-step chemical conjugation reaction using cross-linkers PA-(PEG) 4 -SPA and EDC/Sulfo-NHS.

\subsection{Nuclear Magnetic Resonance}

The binding of AT1 peptide with HSA was initially characterized by ${ }^{1} \mathrm{H}-\mathrm{NMR}$ (Figure 2). The NMR spectrum of AT1 displays peaks at $6.8-7.0 \mathrm{ppm}$ which are due to the presence of tyrosine residues, while most of the downfield resonance is due to histidine [21]. Peaks at around 3.5-4.0 ppm due to glycine residues visible on AT1 spectrum are also visible on the AT1-HSA spectrum at around $3.5 \mathrm{ppm}$. However, due to the higher molecular weight of HSA (66500 Da) compared to the AT1 peptide (1274 Da), we observe broader peaks for HSA and AT1-HSA. Thus, the ${ }^{1} \mathrm{H}-\mathrm{NMR}$ indicates binding of the AT1 peptide with the HSA.

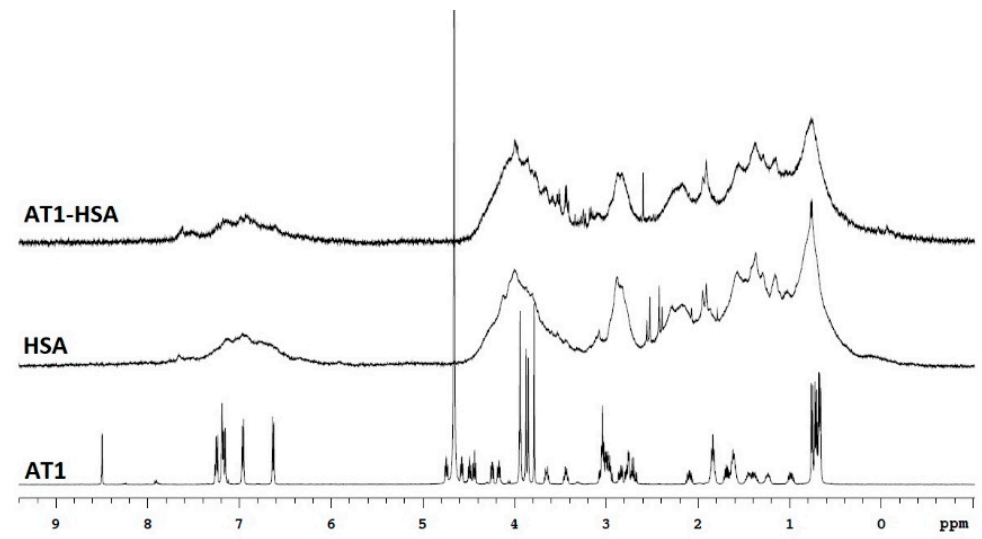

Figure 2. $1 \mathrm{H}$ NMR-based characterization of AT1-HSA, HSA, and AT1 peptide. The AT1 peptide exhibits a spectrum with sharp peaks at $\delta=0.5-1.0, \delta=1.1-2.1, \delta=2.8-3.8, \delta=4.0-5.0$, and $\delta=6.3-7.3$. The peaks at $\delta=6.8$ due to tyrosine and around $\delta=3.8-4.0$ due to glycine from the AT1 peptide can be seen on the AT1-HSA spectrum around $\delta=3.5-4.0$ and $6.8 \mathrm{ppm}$.

\subsection{Mass Spectrometry}

To validate the conjugation of AT1 with HSA, MALDI-TOF-MS was performed to compare the average molecular weight change between HSA and AT1-HSA. The massto-charge ratio $(\mathrm{m} / \mathrm{z})$ of the green peak (AT1-HSA) was approximately 5600 higher than the red peak (HSA) (Figure 3). Since the molecular weights of the AT1, PA-(PEG) ${ }_{4}$-SPA, EDC, and Sulfo-NHS are 1274, 435.4, 190, and $217 \mathrm{~g} / \mathrm{mol}$, respectively, it can be inferred 
that several molecules of the AT1 peptide are successfully conjugated to the surface of each HSA molecule.

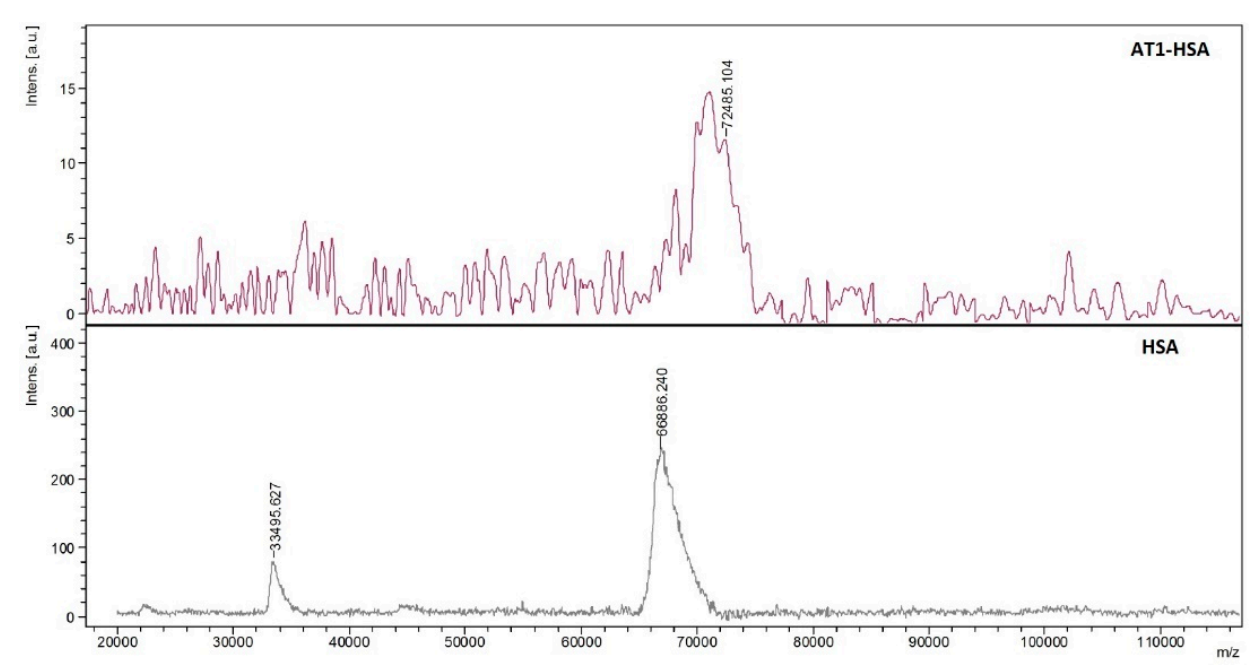

Figure 3. HSA (lower) and AT1-HSA (upper) were analyzed by Matrix-Assisted Laser Desorption/Ionization Time of Flight Mass Spectrometry. The m/z ratio of the AT1-HSA peak was at least 5600 higher than that of the HSA peak, which demonstrated that AT1 was successfully conjugated to the surface of HSA.

\subsection{Quantification of the AT1 Peptide}

The quantity of AT1-peptide attached to the HSA molecule was determined by UVvisible spectrophotometry. Results showed that $82.9 \pm 1.6 \%$ of the starting concentration of the AT1-peptide remained bound to the surface of HSA after the chemical conjugation reaction.

\subsection{Characterization of the AT1-HSA-MRN-NPS}

The size of the nanoparticles was determined by DLS and zeta potential was measured by laser Doppler anemometry. The particle size and zeta potential of AT1-nanoparticle formulation at MRN/AT1-HSA $(w / w)$ ratio of 1:10 was $190.2 \pm 5.7 \mathrm{~nm}$ with a zeta potential of $-29.5 \pm 3.7 \mathrm{mV}$. The size of the nanoparticles at MRN/AT1-HSA $(w / w)$ ratio of 1:20 was $205.6 \pm 3.8 \mathrm{~nm}$ with zeta potential of $-27.5 \pm 4.6 \mathrm{mV}$. The size of the nanoparticles at MRN/AT1-HSA $(w / w)$ ratio of $1: 40$ was $225.4 \pm 2.8 \mathrm{~nm}$ with zeta potential of $-20.5 \pm 4.4 \mathrm{mV}$. The size of the nanoparticles at MRN/AT1-HSA $(w / w)$ ratio of 1:80 was $245.6 \pm 3.5 \mathrm{~nm}$ with zeta potential of $-18.7 \pm 6.6 \mathrm{mV}$. These results suggest that as the quantity of MRN bound to the nanoparticles increased, there was reduction in the size of the nanoparticles and the zeta potential became more negative, indicating greater physical stability of the particles. The yield and drug encapsulation efficiency of the AT1-nanoparticles has been summarized in Table 1 .

Table 1. Nanoparticle size, charge, encapsulation efficiency, and yield at various MRN/AT1-HSA $(w / w)$ ratios of nanoparticle preparation.

\begin{tabular}{ccccc}
\hline $\begin{array}{c}\text { MRN/AT1-HSA } \\
(\boldsymbol{w} / \boldsymbol{w})\end{array}$ & $\begin{array}{c}\text { Nanoparticle } \\
\text { Size }(\mathbf{n m})\end{array}$ & $\begin{array}{c}\text { Zeta Potential } \\
\mathbf{( m V )}\end{array}$ & $\begin{array}{c}\text { Encapsulation } \\
\text { Efficiency (\%) }\end{array}$ & Yield (\%) \\
\hline $1: 10$ & $190.2 \pm 5.7$ & $-29.5 \pm 3.7$ & $41.8 \pm 2.2$ & $77 \pm 2.3$ \\
$1: 20$ & $205.6 \pm 3.8$ & $-27.5 \pm 4.6$ & $40.4 \pm 1.5$ & $75 \pm 2.6$ \\
$1: 40$ & $225.4 \pm 2.8$ & $-20.5 \pm 4.4$ & $54.1 \pm 0.7$ & $70 \pm 3.5$ \\
$1: 80$ & $245.6 \pm 3.5$ & $-18.7 \pm 6.6$ & $83.2 \pm 1.2$ & $68 \pm 4.6$ \\
\hline
\end{tabular}

The morphology of the nanoparticles observed by TEM under 17,800× (Figure 4a) and $105,000 \times$ magnification exhibited a near spherical shape with moderately uniform particle 
size and distribution (Figure 4b). Under 135,000 $\times$ magnification, the AT1-HSA-MRN-NPs had a dark core surrounded by a bright membrane, which confirmed the distinct layer of peptide bound to the surface (Figure 4c).

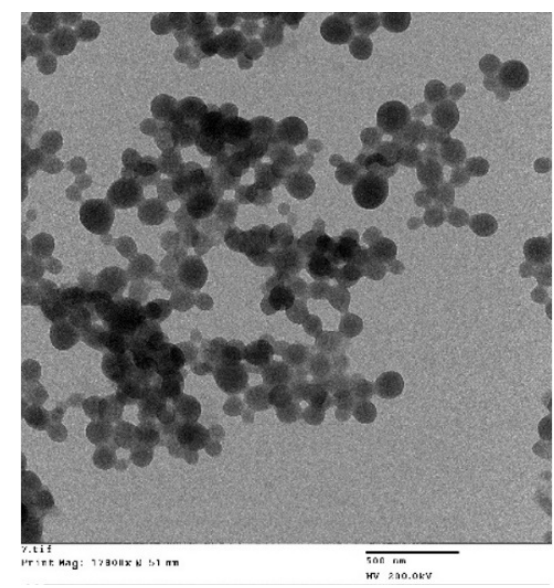

(a)

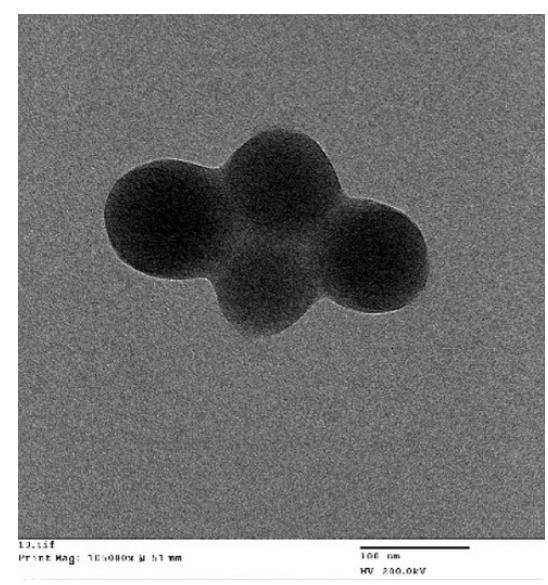

(b)

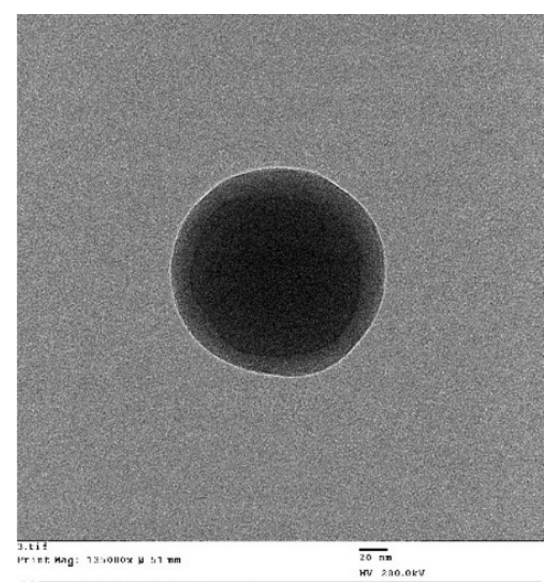

(c)

Figure 4. Nanoparticle surface characterization using TEM analysis: (a) Under magnification of 17,800 $\times$, AT1-HSA-MRN-NPs of size $190.2 \pm 5.7 \mathrm{~nm}$ with a zeta potential of $-29.5 \pm 3.7 \mathrm{mV}($ Scale $=500 \mathrm{~nm})$; (b) Under magnification of 105,000 $\times$, AT1-HSAMRN-NPs with moderately uniform particle size (Scale = $100 \mathrm{~nm}$ ); (c) Under 135,000 $\times$ magnification, the AT1-HSA-MRN-NPs display a dark core surrounded by a bright distinct membrane layer (Scale $=20 \mathrm{~nm}$ ).

The AT1-HSA-MRN-NPs were further tested in vivo for determining pharmacokinetics, biodistribution, safety and toxicity, and cardiac function assessment. In vitro studies on nanoparticle optimization, MRN binding and release, intracellular uptake, and biocompatibility have been studied extensively and reported through prior research and therefore were not repeated in this study $[9,10]$.

\subsection{Pharmacokinetic Parametersv}

To determine MRN pharmacokinetics, female Lewis rats were divided into three groups. Group I received an injection of saline, Group II was injected with AT1-HSA-MRNNPs at a milrinone dose of $50 \mu \mathrm{g} / \mathrm{kg}$ and Group III received MRN Lactate at a milrinone concentration of $50 \mu \mathrm{g} / \mathrm{kg}$. The above dosage was determined from previous studies and keeping aligned with the dosage of milrinone lactate that is clinically administered to heart failure patients $[22,23]$. The milrinone plasma concentration-time curves of the intravenously administered formulations are represented in Figure 5. Results suggest that the MRN Lactate was removed from circulation much quicker than the AT1-HSA-MRNNPs. The MRN Lactate concentration $6 \mathrm{~h}$ post injection was extremely low, however MRN released from the AT1-nanoparticles was detected even $6 \mathrm{~h}$ post injection. The clearance of the AT1-HSA-MRN-NPs was significantly delayed, as shown in Table 2 listing milrinone concentrations $(\mathrm{ng} / \mathrm{mL})$ at the various time points $(0,5,15,30,45,60,120$, and $360 \mathrm{~min})$ for Group II injected with AT1-MRN-HSA-NPs and Group III injected with MRN Lactate, both intravenously. 


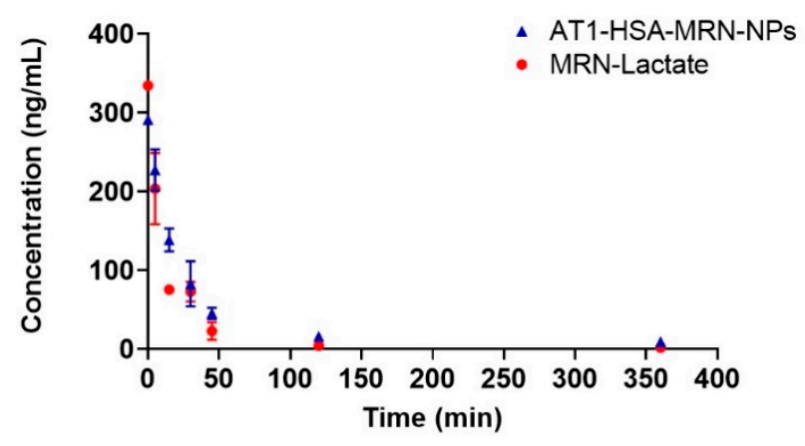

Figure 5. Pharmacokinetics of AT1-HSA-MRN-NPs (Group II) and MRN-Lactate (Group III) at an initial MRN dose of $50 \mu \mathrm{g} / \mathrm{kg}$ in vivo.

Table 2. Comparing milrinone concentration $(\mathrm{ng} / \mathrm{mL})$ at various time points between AT1-MRNHSA-NPs (Group II) and MRN Lactate (Group III) injected intravenously in female Lewis rats. Table shows a representative result of mean $\pm \mathrm{SD}(n=4)$.

\begin{tabular}{ccc}
\hline $\begin{array}{c}\text { Time } \\
(\mathbf{m i n} .)\end{array}$ & $\begin{array}{c}\text { AT1-HSA-MRN-NPs } \\
(\mathbf{n g} / \mathbf{m L})\end{array}$ & $\begin{array}{c}\text { MRN Lactate } \\
(\mathbf{n g} / \mathbf{m L})\end{array}$ \\
\hline 0 & 291.2 & 334.2 \\
5 & $227.3 \pm 26.2$ & $203.5 \pm 45.3$ \\
15 & $138.5 \pm 14.5$ & $75.4 \pm 6.2$ \\
30 & $82.6 \pm 28.5$ & $72.6 \pm 12.4$ \\
45 & $45.3 \pm 7.1$ & $22.9 \pm 11.2$ \\
120 & $15.9 \pm 3.5$ & $4.1 \pm 1.5$ \\
360 & $9.1 \pm 0.9$ & $1.6 \pm 0.1$ \\
\hline
\end{tabular}

The mean pharmacokinetic parameters were calculated using a non-compartmental method and have been listed in Table 3. For AT1-HSA-MRN-NPs, the MRT was $123.7 \mathrm{~min}$, AUC was $183.9 \mathrm{ng}^{*} \mathrm{~h} / \mathrm{mL}$, half-life was $101.3 \mathrm{~min}$, and clearance rate was $0.24 \mathrm{~L} /\left(\mathrm{kg}^{*} \mathrm{~h}\right)$. For MRN Lactate, the MRT was $49.1 \mathrm{~min}$, AUC was $104.3 \mathrm{ng}$ (h/mL, half-life was $64.7 \mathrm{~min}$, and clearance rate was $0.47 \mathrm{~L} /\left(\mathrm{kg}^{*} \mathrm{~h}\right)$.

Table 3. Pharmacokinetic parameters of AT1-HSA-MRN-NPs and MRN Lactate at MRN dose $50 \mu \mathrm{g} / \mathrm{kg}$. $\mathrm{C}_{0}$ : concentration at time $0 ; \mathrm{C}_{\max }$ : maximum concentration; $\mathrm{t}_{1 / 2}$ : half-life of plasma; MRT: mean residence time, AUC: area under the curve, Vz: apparent volume of distribution at elimination; Vss: apparent volume of distribution at steady state; CL: clearance.

\begin{tabular}{|c|c|c|}
\hline \multirow{2}{*}{$\begin{array}{l}\text { Pharmacokinetic } \\
\text { Parameters }\end{array}$} & \multicolumn{2}{|c|}{ MRN Dose: 50 g/kg } \\
\hline & MRN-Lactate & AT1-HSA-MRN-NPs \\
\hline $\mathrm{C}_{0}(\mathrm{ng} / \mathrm{mL})$ & 203.5 & 291.2 \\
\hline $\mathrm{C}_{\max }(\mathrm{ng} / \mathrm{mL})$ & 334.3 & 227.3 \\
\hline $\mathrm{t}_{1 / 2}(\mathrm{~min})$ & 64.7 & 101.3 \\
\hline MRT (min) & 49.1 & 123.7 \\
\hline $\mathrm{AUC}_{0-\mathrm{t}}\left(\mathrm{ng}{ }^{*} \mathrm{~h} / \mathrm{mL}\right)$ & 104.3 & 183.9 \\
\hline $\mathrm{AUC}_{0-\infty}\left(\mathrm{ng}^{*} \mathrm{~h} / \mathrm{mL}\right)$ & 106.7 & 206.1 \\
\hline $\mathrm{Vz}(\mathrm{L} / \mathrm{kg})$ & 0.73 & 0.59 \\
\hline Vss (L/kg) & 0.38 & 0.5 \\
\hline $\mathrm{CL}\left(\mathrm{L} /\left(\mathrm{kg}^{*} \mathrm{~h}\right)\right)$ & 0.47 & 0.24 \\
\hline
\end{tabular}

\subsection{Tissue Distribution Study}

The concentration of MRN in AT1-HSA-MRN-NPs and MRN Lactate was investigated after intravenous administration of the formulations in female Lewis rats. The amounts of MRN detected at $2 \mathrm{~h}$ time point in different tissues such as heart, lungs, kidneys, and liver are shown in Figure 6. The level of MRN uptake for the lungs, kidneys, and liver 
was greater in the MRN Lactate group (Group III) than in the AT1-HSA-MRN-NP group (Group II). For lungs, the MRN detected in the MRN Lactate group vs. AT1-HSA-MRN-NPs was $7.55 \pm 0.01$ vs. $7.88 \pm 0.09 \mathrm{ng} / \mathrm{mL}$, for kidneys was $4.80 \pm 0.6$ vs. $2.64 \pm 0.30 \mathrm{ng} / \mathrm{mL}$, and for liver was $2.44 \pm 0.23$ vs. $1.27 \pm 0.14 \mathrm{ng} / \mathrm{mL}$. This is due to the passive targeting of albumin nanoparticles. Interestingly, the amount of MRN detected in the heart was significantly higher $(p<0.01)$ in case of the AT1-HSA-MRN-NPs group $(7.88 \pm 1.4 \mathrm{ng} / \mathrm{mL})$ vs. the MRN-Lactate $(2.00 \pm 1.01 \mathrm{ng} / \mathrm{mL})$. The MRN uptake by the heart was significantly greater than the MRN detected in other tissues for Group II, which indicates the target specificity of the nanoparticles towards the AT1 receptors present on the myocardium. For the same group, there was no significant difference in MRN uptake between the heart and lungs.

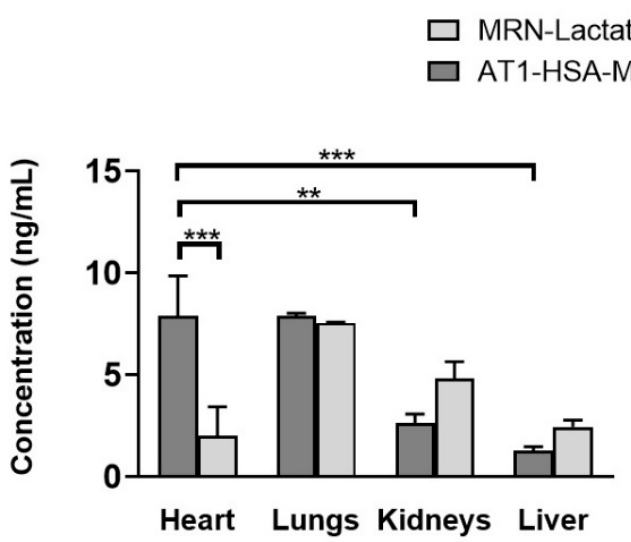

Figure 6. Tissue distribution of AT1-HSA-MRN-NPs and MRN-Lactate at an initial MRN dose of $50 \mu \mathrm{g} / \mathrm{kg}$ in vivo. The graph shows a representative result of mean $\pm \operatorname{SD}(n=4) .{ }^{* *} p<0.001$ was considered highly significant and ${ }^{* *} p<0.01$ was considered significant based on Tukey's post hoc analysis.

\subsection{Cardiac Function Assessment}

The echocardiographic parameters were analyzed by comparing the baseline values with the subsequent echocardiographic measurements taken post surgery and injection (Figure 7). The percentage left ventricular ejection fraction (LVEF \%) and percentage left ventricular fractional shortening (LVFS \%) were measured for all the groups at preoperation/ligation, $48 \mathrm{~h}$ post ligation, $60 \mathrm{~min}$ post treatment injections, $24 \mathrm{~h}$ post injections, $48 \mathrm{~h}$ post injections and 1-week post injection (Tables 4 and 5). The EF was not significantly different between the groups preoperatively (baseline) and $48 \mathrm{~h}$ post ligation. A two-way ANOVA determined that the EF at 60 min post injection for Group II $(84.3 \pm 2.9 \%)$ was higher than Group $1(68.6 \pm 2.2 \%)(p=0.0003)$ and Group $4(70.1 \pm 2.3 \%)(p=0.0006)$ however, not significantly different than Groups $3(p=0.3846)$ and $5(\mathrm{p}=0.1744)$. At $24 \mathrm{~h}$ post injection, the EF for Group 2 remained consistent until 1-week post ligation. At $24 \mathrm{~h}$ post treatment, there was a reduction in EF for Group $3(70.6 \pm 3.6 \%)$, which was significantly lower $(p=0.0152)$ than Group $2(84.2 \pm 4.8 \%)$ in addition to Groups 1 and 4. This effect stayed consistent at $48 \mathrm{~h}$ post injection with a reduction in Group 5 (72.7 \pm $2.3 \%)$ EF as well, which was lower $(p=0.0114)$ than that of Group $2(83.1 \pm 3.6 \%)$. This indicates that the intravenous (i.v.) delivery route worked better for targeted drug delivery as compared to the subcutaneous route of delivery in terms of sustained drug release. At 1-week post injections, there was no significant differences between Groups 2, 3, and 5, however EF of Groups 2 was higher than Group $1(p=0.0038)$ and $4(p=0.0259)$.

Similarly, for FS measurements, there was no significant differences amongst the groups either pre-ligation or $48 \mathrm{~h}$ post ligation (Figure 8). However, in accordance with EF measurements, the FS for Group $2(50.1 \pm 3.8 \%)$ was significantly higher than that of Groups $1(32.8 \pm 1.7 \%)(p=0.0016)$ and $4(34.7 \pm 4.0 \%)(p=0.0037)$ at $60 \mathrm{~min}$ post injection, with no significant difference from Groups 3 and 5. The FS of Group 3 was 
reduced at $24 \mathrm{~h}(33.6 \pm 3.9 \%)$ and $48 \mathrm{~h}(30.2 \pm 3.9 \%)$ post injection, which was significantly lower $(p=0.0014)$ than that of Group 2 at those time points $(50.4 \pm 3.1 \%$ and $46.5 \pm 3.1 \%$, respectively). A similar effect was observed for Group 5 as well in which the FS was reduced significantly in comparison to Group 2 at $24 \mathrm{~h}(40.5 \pm 2.8 \%)(p=0.0107)$ and $48 \mathrm{~h}$ $(34.8 \pm 1.7 \%),(p=0.0029)$. At 1 -week post injections, there was reduction in FS of Group 2 with no significant differences amongst the groups, except with Group $4(p=0.0182)$.
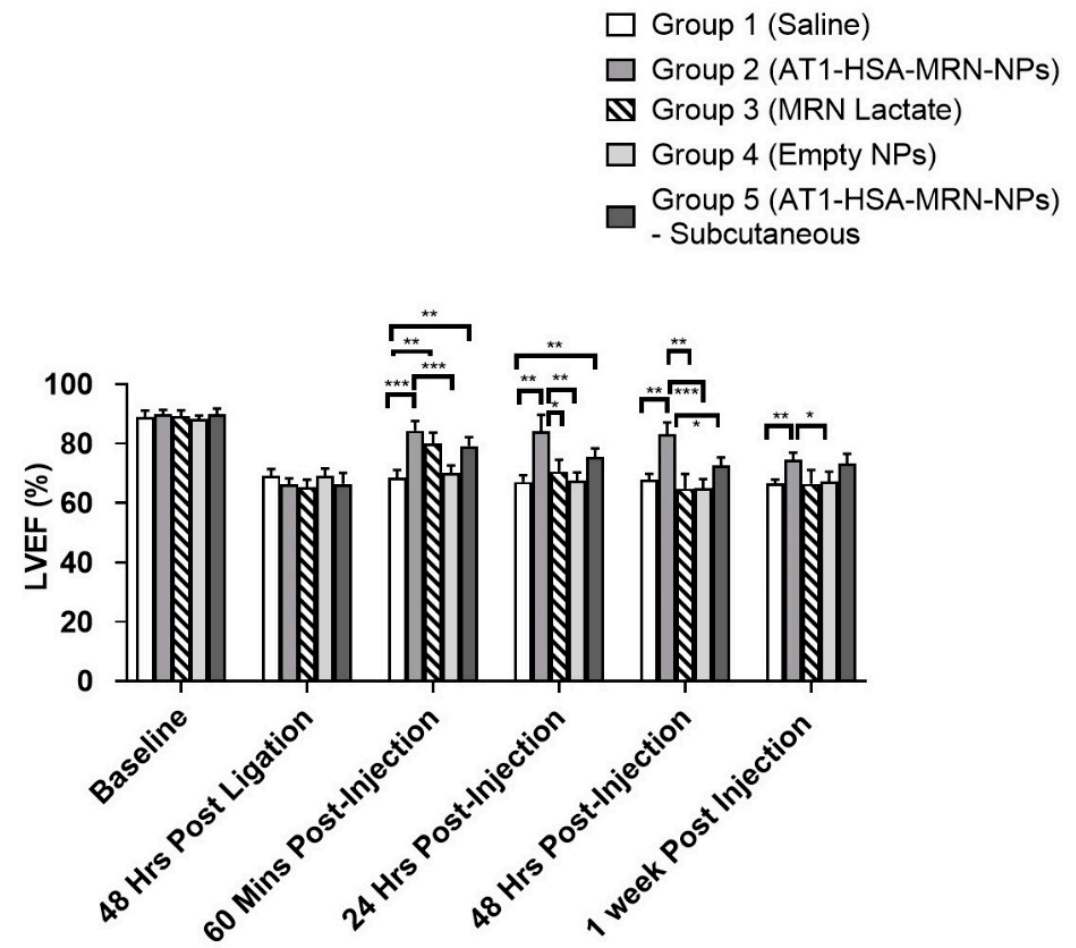

Figure 7. Percentage LVEF measurements for Groups 1, 2, 3, 4, and 5 at baseline, 48 h post ligation, $60 \mathrm{~min}, 24 \mathrm{~h}, 48 \mathrm{~h}$, and 1-week post injections. The graph shows a representative result of mean $\pm \mathrm{SD}$ $(n=5) .{ }^{* *} p<0.001,{ }^{* *} p<0.01$ and ${ }^{*} p<0.05$ were considered significant based on Tukey's post hoc analysis.

Table 4. Percentage LVEF measurements for Groups 1, 2, 3, 4, and 5 at various timepoints.

\begin{tabular}{|c|c|c|c|c|c|}
\hline \multicolumn{6}{|c|}{ Left Ventricular Ejection Fraction (LVEF) Shown as \% } \\
\hline & $\begin{array}{c}\text { Group } 1 \\
\text { (Control) }\end{array}$ & $\begin{array}{c}\text { Group } 2 \\
\text { (AT1-HSA-MRN- } \\
\text { NPs-i.v. } \\
\text { Injection) }\end{array}$ & $\begin{array}{l}\text { Group 3 } \\
\text { (MRN } \\
\text { Lactate-i.v. } \\
\text { Injection) }\end{array}$ & $\begin{array}{c}\text { Group } 4 \\
\text { (Empty NPs) }\end{array}$ & $\begin{array}{c}\text { Group 5 } \\
\text { AT1-HSA-MRN-NPs- } \\
\text { Subcutaneous } \\
\text { Injection) }\end{array}$ \\
\hline $\begin{array}{l}\text { Baseline-Pre- } \\
\text { Ligation }\end{array}$ & $88.8 \pm 2.1$ & $89.9 \pm 1.3$ & $88.2 \pm 1.8$ & $88.4 \pm 0.9$ & $74.9 \pm 1.7$ \\
\hline 48 h Post Ligation & $69.1 \pm 2.0$ & $66.1 \pm 1.9$ & $65.3 \pm 2.3$ & $69.1 \pm 2.2$ & $66.4 \pm 3.3$ \\
\hline $\begin{array}{l}60 \text { min Post } \\
\text { Injection }\end{array}$ & $68.6 \pm 2.2$ & $84.3 \pm 2.9^{* * *}$ & $80.1 \pm 3.3^{* *}$ & $70.1 \pm 2.3$ & $79.2 \pm 2.7^{* *}$ \\
\hline $24 \mathrm{~h}$ Post Injection & $67.1 \pm 2.1$ & $84.2 \pm 4.8^{* *}$ & $70.6 \pm 3.6$ & $67.5 \pm 2.5$ & $75.5 \pm 2.6^{* *}$ \\
\hline $48 \mathrm{~h}$ Post Injection & $67.7 \pm 1.8$ & $83.1 \pm 3.6^{* *}$ & $64.8 \pm 4.3$ & $64.9 \pm 2.7$ & $72.7 \pm 2.3$ \\
\hline $\begin{array}{l}\text { 1-week Post } \\
\text { Injection }\end{array}$ & $66.7 \pm 1.1$ & $74.5 \pm 2.1^{* *}$ & $66.1 \pm 4.2$ & $67.2 \pm 2.9$ & $73.3 \pm 2.9 *$ \\
\hline
\end{tabular}

The data have been presented as mean $\pm \mathrm{SD}(n=5) .{ }^{* * *} p<0.001,{ }^{* *} p<0.01,{ }^{*} p<0.05$ were considered significant based on Tukey's post hoc analysis. The comparisons are with respect to the control Group 1. 
Table 5. Percentage LVFS measurements for Groups 1, 2, 3, 4, and 5 at various timepoints.

\begin{tabular}{|c|c|c|c|c|c|}
\hline \multicolumn{6}{|c|}{ Left Ventricular Fractional Shortening (LVFS) Shown as \% } \\
\hline & $\begin{array}{c}\text { Group } 1 \\
\text { (Control) }\end{array}$ & $\begin{array}{c}\text { Group } 2 \\
\text { (AT1-HSA-MRN- } \\
\text { NPs-i.v. } \\
\text { Injection) }\end{array}$ & $\begin{array}{c}\text { Group 3 } \\
\text { (MRN } \\
\text { Lactate-i.v. } \\
\text { Injection) }\end{array}$ & $\begin{array}{c}\text { Group } 4 \\
\text { (Empty NPs) }\end{array}$ & $\begin{array}{c}\text { Group 5 } \\
\text { AT1-HSA-MRN-NPs- } \\
\text { Subcutaneous } \\
\text { Injection) }\end{array}$ \\
\hline $\begin{array}{c}\text { Baseline-Pre- } \\
\text { Ligation }\end{array}$ & $52.6 \pm 2.9$ & $53.6 \pm 2.1$ & $52.6 \pm 2.7$ & $51.1 \pm 1.3$ & $54.6 \pm 2.2$ \\
\hline $48 \mathrm{~h}$ Post Ligation & $33.1 \pm 1.5$ & $29.8 \pm 1.0$ & $34.3 \pm 2.7$ & $31.2 \pm 1.3$ & $30.7 \pm 2.5$ \\
\hline $\begin{array}{l}60 \text { min Post } \\
\text { Injection }\end{array}$ & $32.8 \pm 1.7$ & $50.1 \pm 3.8^{* *}$ & $45.6 \pm 3.2 * *$ & $34.7 \pm 4.0$ & $47.1 \pm 3.9^{* *}$ \\
\hline $24 \mathrm{~h}$ Post Injection & $31.5 \pm 1.2$ & $50.4 \pm 3.1^{* * *}$ & $33.6 \pm 3.9$ & $30.9 \pm 2.4$ & $40.5 \pm 2.8^{* *}$ \\
\hline 48 h Post Injection & $31.7 \pm 1.0$ & $46.5 \pm 3.1^{* *}$ & $30.2 \pm 3.9$ & $30.1 \pm 1.5$ & $34.8 \pm 1.7$ \\
\hline $\begin{array}{l}\text { 1-week Post } \\
\text { Injection }\end{array}$ & $31.3 \pm 1.5$ & $37.0 \pm 2.7$ & $30.8 \pm 2.8$ & $29.6 \pm 1.1$ & $35.9 \pm 3.1$ \\
\hline
\end{tabular}

The data have been presented as mean $\pm \mathrm{SD}(n=5)$. The data have been presented as mean $\pm \mathrm{SD}(n=5) .^{* * *} p<0.001,{ }^{* *} p<0.01$, were considered significant based on Tukey's post hoc analysis. The comparisons are with respect to the control Group 1.

Group 1 (Saline)

Group 2 (AT1-HSA-MRN-NPs)

$\mathbf{\Delta}$ Group 3 (MRN Lactate)

Group 4 (Empty NPs)

Group 5 (AT1-HSA-MRN-NPs)

- Subcutaneous

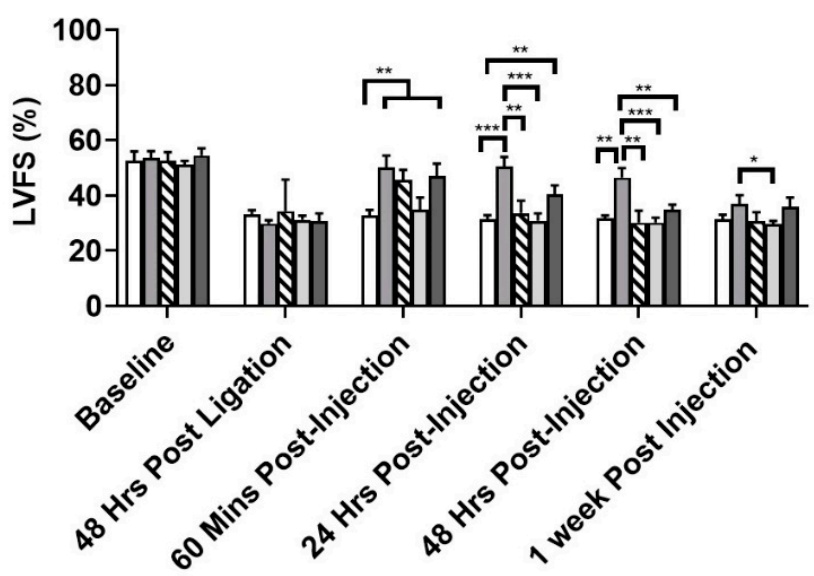

Figure 8. Percentage LVFS measurements for Groups 1, 2, 3, 4, and 5 at baseline, $48 \mathrm{~h}$ post ligation, $60 \mathrm{~min}, 24 \mathrm{~h}, 48 \mathrm{~h}$, and 1-week post injections. The data have been presented as mean $\pm \mathrm{SD}(n=5)$. *** $p<0.001$ was considered highly significant and ${ }^{* *} p<0.01,{ }^{*} p<0.05$ was considered significant based on Tuckey's post hoc analysis.

\subsection{Milrinone Quantification from Rat Plasma}

Both milrinone and amrinone were detected by LC-MS. Results showed that at $24 \mathrm{~h}$ post treatment, the milrinone detected in plasma in Group 2 was significantly greater than in Groups 3 and 5 (Group 2: $16.5 \pm 4.6 \mathrm{ng} / \mathrm{mL}$ vs. Group 3: $0.3 \pm 0.1 \mathrm{ng} / \mathrm{mL}$ and Group 5: $1.2 \pm 0.1 \mathrm{ng} / \mathrm{mL}$ ) (Figure 9). 


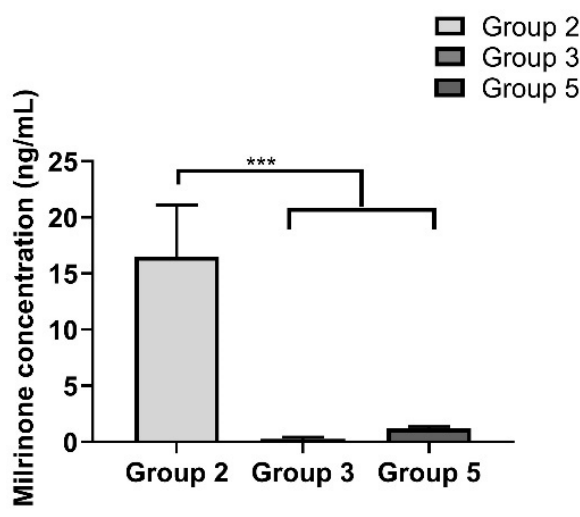

Figure 9. Milrinone levels detected in plasma $24 \mathrm{~h}$ post treatment for Groups 2, 3, and 5. The graph shows a representative result of mean $\pm \mathrm{SD}(n=3)$. ${ }^{* *} p<0.001$ was considered significant based on Tukey's post hoc analysis.

\subsection{Safety and Toxicity of the AT1-HSA-MRN-NPS}

The serum samples collected from the animals were analyzed for markers of safety and toxicity. The liver function and toxicity analysis were performed by analyzing alkaline phosphatase (ALP), aspartate aminotransferase (AST), and alkaline aminotransferase (ALT), respectively (Figure 10a-c). Results show that there were no significant differences in the ALP levels between the groups and all values fall in the normal range of 16-302 U/L for rats. The levels of ALT enzyme for Group 3 were lower than Group $5(p=0.0350)$, but were within the normal range of 20-61 U/L. The AST enzyme levels of Group 2 were elevated as compared to Group $1(p=0.0273)$, however, were well within the normal range of 39-111 U/L and did not differ significantly between the control and other treatment groups. The GGT levels were also measured and were found to be in range $(0-6 \mathrm{U} / \mathrm{L})$ for all groups. To evaluate the renal function, creatinine and urea were analyzed (Figure 10d-e). It was found that though there was no significant difference in the creatinine levels amongst the groups, these values were lower than the normal range of $50-73 \mu \mathrm{mol} / \mathrm{L}$. This is indicative of renal dysfunction which is commonly associated with heart disease. There were significant differences in urea levels between the Groups 1 and $4(p=0.0096)$ and Groups 4 and $5(p=0.0096)$, however the levels were found to be in the normal range overall (3.2-7.5 mmol/L). 


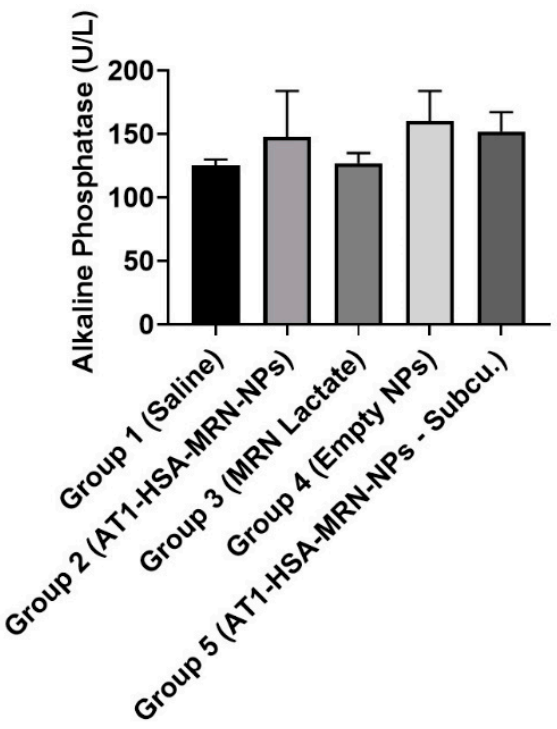

(a)

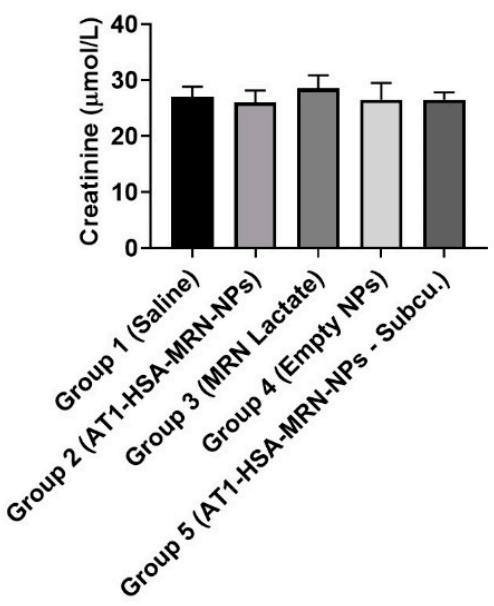

(d)

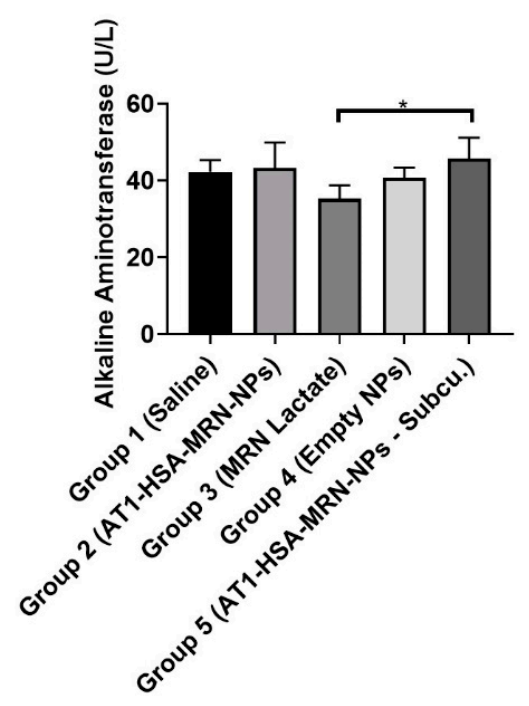

(b)

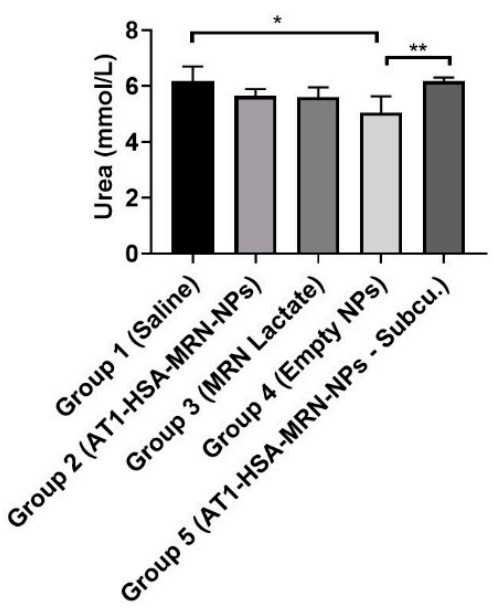

(e)

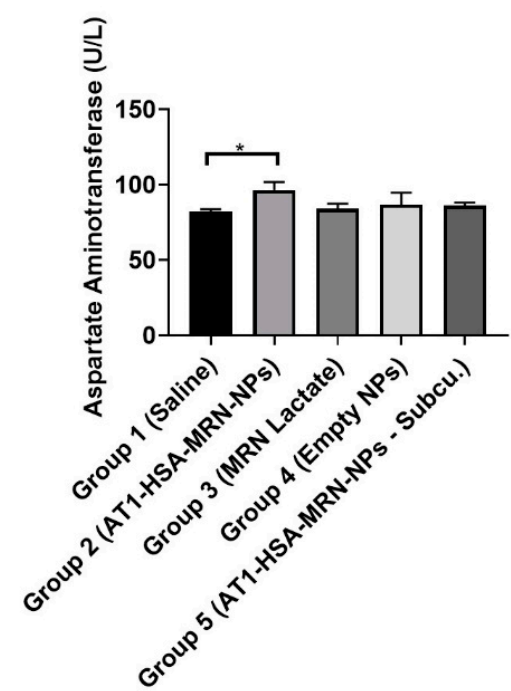

(c)

Figure 10. Serum analysis performed as a safety test comparing the (a) ALP (U/L); (b) ALT (U/L); (c) AST (U/L) as liver function tests and $(\mathbf{d})$ creatinine $(\mu \mathrm{mol} / \mathrm{L}) ;(\mathbf{e})$ urea $(\mathrm{mmol} / \mathrm{L})$ as kidney function tests. The graph shows a representative result of mean $\pm \mathrm{SD}(n=5) .{ }^{* *} p<0.01,{ }^{*} p<0.05$ were considered significant based on Tukey's post hoc analysis.

\subsection{Serum Cytokine Measurements}

The serum cytokine levels of IL-6, IL-10, and TNF- $\alpha$ were measured at 1 -week post treatment (Figure 11). Serum TNF- $\alpha$ levels were significantly different amongst the groups with control Groups 1 at $40.7 \pm 3.8 \mathrm{pg} / \mathrm{mL}$ and Group 4 at $40.3 \pm 1.8 \mathrm{pg} / \mathrm{mL}$, which was higher $(p<0.0001)$ than that of Group $2(9.2 \pm 0.6 \mathrm{pg} / \mathrm{mL})$, Group $3(17.1 \pm 2.8 \mathrm{pg} / \mathrm{mL}$, and Group 5 $(11.1 \pm 0.9 \mathrm{pg} / \mathrm{mL})$ (Figure). The Group 2 and Group $5 \mathrm{TNF}-\alpha$ levels were significantly higher $(p<0.05)$ than the serum TNF- $\alpha$ levels of Group $3(p=0.0442)$, with no significant difference between Groups 2 and 5. Serum IL-6 levels were significantly different between the groups. Group 1 and Group 4 IL-6 levels $(58.2 \pm 11.3 \mathrm{pg} / \mathrm{mL}$ and $57.1 \pm 12.8 \mathrm{pg} / \mathrm{mL})$ were significantly higher $(p<0.05)$ than that of Group $2(24.9 \pm 6.2 \mathrm{pg} / \mathrm{mL})$, Group $3(39.3 \pm 2.7 \mathrm{pg} / \mathrm{mL})$, and Group $5(22.6 \pm 5.4 \mathrm{pg} / \mathrm{mL})(p=0.0137)$. There were no significant differences between Groups 1 and 4 and between Groups 2,3, and 5. However, the anti-inflammatory cytokine IL-10 levels in Groups $1(67.3 \pm 15.5 \mathrm{pg} / \mathrm{mL})$ and $4(71.1 \pm 12.1 \mathrm{pg} / \mathrm{mL})$ were significantly lower $(p<0.05)$ than Group $2(184.4 \pm 32.7 \mathrm{pg} / \mathrm{mL})$, Group $3(146.1 \pm 24.7 \mathrm{pg} / \mathrm{mL})$, and Group 5 (181.6 \pm 77.3 pg $/ \mathrm{mL})$. 


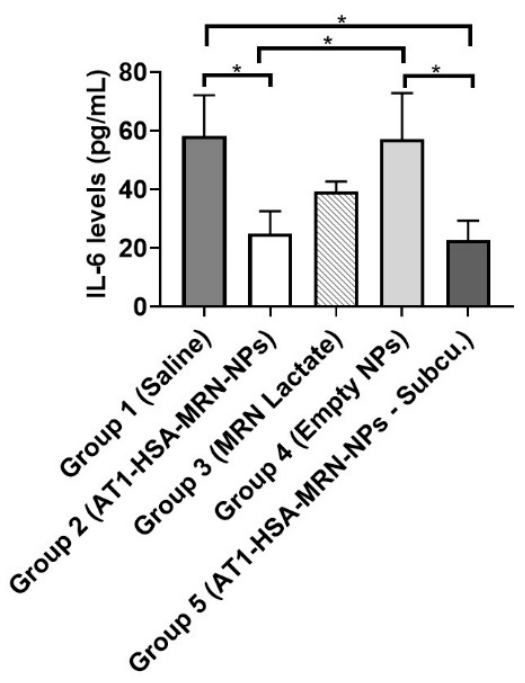

(a)

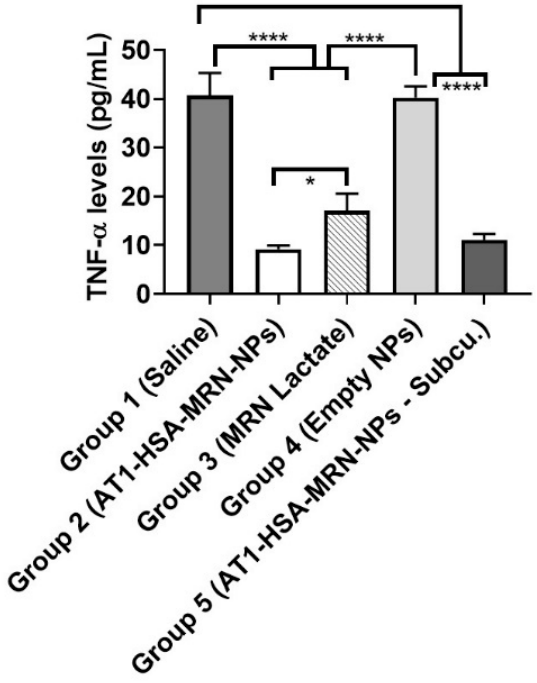

(b)

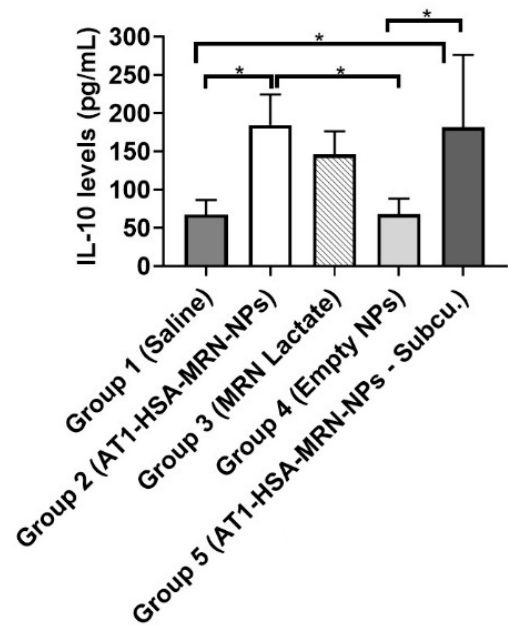

(c)

Figure 11. Serum cytokine levels for (a) IL-6 (pg/mL), (b) TNF- $\alpha$ (pg/mL), and (c) IL-10 (pg/mL). Groups 2 and 5 had significantly lower levels of IL- 6 and TNF- $\alpha$ and significantly higher levels of IL-10 compared with other groups. The data have been presented as mean $\pm \mathrm{SD}(n=5) .{ }^{* * *} p<0.0001$ was considered highly significant and ${ }^{*} p<0.05$ was considered significant based on Tukey's post hoc analysis.

\section{Discussion}

Nanoparticle-based technology has advanced significantly in the last few decades with numerous applications in the field of medicine and healthcare. Nanoparticle-based drug delivery systems have shown innovative approaches of loading and delivering drugs, genes, hormones, small molecules, etc., in both targeted and non-targeted ways [12,24]. This allows for targeted and site-specific delivery, controlled drug release, enhanced bioavailability, improved safety, and reduced toxicity $[5,6,25]$. Though most of these formulations have been tested and approved for use in cancer, their use in cardiovascular applications such as congestive heart failure is equally promising with maximum focus on in-stent restenosis and the use of microparticles for drug delivery [26].

In the present study, AT1-HSA-MRN-NPs have been successfully prepared as a novel heart-targeted formulation for site-specific delivery of MRN using albumin nanoparticles, surface functionalized with the ligand, AT1 peptide. Under conditions of MI and HF, AT1 receptors, present on the myocardium, are found to be overexpressed $[8,17,27]$. Thus, the AT1 receptors, specific for the angiotensin II peptide, facilitate uptake of the AT1-HSA-MRN-NPs through receptor-mediated endocytosis allowing for site-specific unloading of the MRN drug. The albumin protein is a heterodimer with sites for binding many hydrophobic and hydrophilic molecules along with active functional groups such as amino and carboxylic groups for covalent conjugation [28,29]. Exploiting these properties, the HSA molecule was first surface-modified to bind the AT1 ligand using PA-(PEG) ${ }_{4}$-SPA, EDC, and Sulfo-NHS as crosslinkers. This was confirmed through NMR and mass spectrometry which indicated that AT1 was bound to the HSA molecule. UVvisible spectrophotometry analysis further revealed that approximately $83 \%$ of the AT1 peptide remained bound to albumin post the covalent chemical conjugation treatment and purification.

The newly synthesized AT1-HSA was used to bind MRN and prepare AT1-HSAMRN-NPs of particle size $190.2 \pm 5.7 \mathrm{~nm}$ and zeta potential of $-29.5 \pm 3.7 \mathrm{mV}$. It is known that the optimal nanoparticle size to avoid rapid clearance from the body by the RES and macrophages is up to $250 \mathrm{~nm}$ with a highly positive or highly negative surface charge $[30,31]$. The particles developed in this study were reproducible with the intended nanoparticle diameter. Through our previous studies, we have successfully confirmed the binding and release of MRN from the nanoparticles as well as the in vitro safety and 
intracellular uptake characteristics [10]. Hence, these studies were not repeated and instead focused on in vivo evaluation.

Typically, post intravenous injections, a controlled and sustained drug release is desired as opposed to a burst release effect. A sustained nanoparticle-drug release eliminates the requirement of a continuous drug infusion or multiple drug injections for treatment. The pharmacokinetics of the AT1-HSA-MRN-NPs and MRN Lactate were studied in a rat model at MRN dose of $50 \mu \mathrm{g} / \mathrm{kg}$ in a $0.25 \mathrm{~mL}$ i.v. injection at $0,5,15,30,45,120$, and $360 \mathrm{~min}$. Compared to MRN Lactate, the AT1-HSA-MRN-NPs showed a higher AUC and prolonged residence of the MRN in blood, exhibiting the sustained release desired. Further, the higher accumulation of the drug in the heart at $2 \mathrm{~h}$ demonstrated that the nanoparticles could be targeted to the heart and reduce the side effects of the drug to other organs. Clinically, heart failure patients are given MRN Lactate at a milrinone concentration of $50 \mathrm{\mu g} / \mathrm{kg}$ [23]. Hence, keeping in alignment with the above dosage and previous studies, the above dosage was used for this study [22]. Studying other higher or lower doses was beyond the scope of this work and will be studied in the future. When MRN Lactate is intravenously injected, the direct interaction of the drug results in its fast elimination, however, loading the drug onto nanoparticles prevents exposure to blood components, acting as a reservoir for a maintaining a controlled release over time. Thus, it may be concluded that the nanoparticles improve the delivery of MRN with prolonged drug retention and targeted uptake by the tissue, in vivo.

Milrinone has been widely used for the treatment congestive heart failure resulting in a low cardiac output, right ventricular failure, and pulmonary tension [23,32]. For patients with end stage heart failure, awaiting heart transplantation or ventricular assist devices, milrinone is used as a long-term continuous infusion [33,34]. In this study, the recovery of heart function was evaluated by measuring both LVEF and LVFS. Both LVEF and LVFS first decreased in response to the infarction created for $48 \mathrm{~h}$. On injecting the formulations, the LVEF increased significantly for Groups 2, 3 and Group 5, when observed at $60 \mathrm{~min}$ post treatment, with no significant difference in Groups 1 and 4 . There was no significant change in the LVEF of Group 2 until $48 \mathrm{~h}$ post treatment, however, the effect of MRN Lactate began to decrease with a reduction in LVEF over $48 \mathrm{~h}$ and 1 week. There were no significant variations between Group 2 and 5 . Thus, the subcutaneous route of delivery did not show any difference from the intravenous delivery route. There was a similar trend in the LVFS parameter as well. It can be concluded that the AT1-HSA-MRN-NPs helped improve the cardiac function post heart failure. These results were in alignment with a similar study done using microparticles containing MRN Lactate [22]. In fact, in the current study, the effect of the sustained MRN release from the nanoparticles was visible for up to 7 days post treatment, indicated by the ejection fraction and fractional shortening. Though the milrinone dose of $50 \mu \mathrm{g} / \mathrm{kg}$ was consistent with previous studies, it is anticipated that injecting a higher dose of MRN will improve the drug release behaviour and deliver a larger quantity of drug in lesser time, without a cytotoxic effect.

Previous studies were mainly focused on determining the tissue levels of cytokines post infarction and not the serum levels. Hence, the cytokine levels in serum were determined with a focus on IL-6, IL-10, and TNF- $\alpha$. The IL- 6 and TNF- $\alpha$ levels were elevated in the infarcted myocardium as a result of remodelling, whereas the IL-10 levels were reduced. The groups treated with AT1-HSA-MRN-NPs had significantly reduced IL- 6 and TNF- $\alpha$, whereas the cardioprotective anti-inflammatory cytokine IL-10 was higher. Though, it is usual to observe higher pro-inflammatory cytokine levels even 1-week post infarction [13]. So, a beneficial effect of the novel nanoparticle formulation could be observed with the reduction in pro-inflammatory cytokines and elevation of the anti-inflammatory cytokines.

It can be concluded that this novel targeted nanoparticle formulation presents a new approach towards the treatment of congestive heart failure. This is the first study to deliver a cardiac inotropic drug in a targeted manner using biodegradable nanoparticles, displaying the effectiveness of the nanoparticle formulation in comparison with the free drug. Though, the nanoparticle formulation was delivered intravenously and subcutaneously 
in this study, an intranasal route of delivery could also be evaluated as a non-invasive procedure for future work. To accomplish the same, further optimization of the nanoparticle formulation will be needed to achieve a particle size of less than $100 \mathrm{~nm}$ to prevent capillary clogging. Another limitation of this study is that any potential side effects associated with the use of MRN, such as arrhythmias, have not been studied in comparison to the nanoparticle formulation, when tested in vivo. This can be addressed by studying toxicity and cardiac function at various MRN doses. This study must be tested in male rats as well as female rats to study the impact of gender differences in the cardiovascular function and pharmacokinetics. The biodistribution study must be performed in organs other than heart, liver, kidney, and lungs, to understand passive targeting of the targeted nanoparticle formulation. Lastly, a large scale and long-term study is required to study the overall treatment efficacy of the targeted nanoparticle formulation and evaluate the improvement in cardiac function upon its use.

Though in the current study, targeted albumin nanoparticles were synthesized to deliver a drug, it is anticipated that the effect of this treatment could be further enhanced by using this nanoparticle system to also deliver genes or growth factors in addition to drugs, promoting myocardial regeneration. Additionally, it has been reported that the phosphodiesterase- 3 varies across different species. Thus, investigating the effects of this novel nanoparticle formulation would be useful in developing a comprehensive understanding of the species variation.

\section{Materials and Methods}

\subsection{Materials}

Human serum albumin ( $>97 \%$ lyophilized) was purchased from Sigma Aldrich (Oakville, ON, Canada). Glutaraldehyde ( $25 \%$ aq. solution) was purchased from Alfa Aesar (Cedarlane, Burlington, ON, Canada). Milrinone was purchased from Selleck Chemicals (Burlington, ON, Canada). EDC, Sulfo-NHS were purchased from Thermo Fisher Scientific (Missisauga, ON, Canada) Other chemicals were purchased from Fisher Scientific (Nepean, ON, Canada).

\subsection{Synthesis of the AT1 Peptide}

The Angiotensin II Type 1 (AT1) receptor targeting peptide is a chain of eight amino acids Asp-Arg-Val-Tyr-Ile-His-Pro-Phe, and was synthesized by CanPeptide (Pointe-Claire, $\mathrm{QC}$, Canada) as $\mathrm{NH}_{2}$-Gly-Gly-Gly-Gly-Asp-Arg-Val-Tyr-Ile-His-Pro-Phe- $\mathrm{NH}_{2}$ following the sequence mentioned by Dvir et al. [16].

\subsection{Surface Modification of HSA with AT1 Peptide}

The surface of HSA was modified for attachment of the AT1 peptide in a two-step reaction. An aqueous solution of $20 \mathrm{mg} / \mathrm{mL}$ of HSA dissolved in deionized water $(0.3 \mathrm{mM})$ was prepared and reacted with PA-(PEG) 4 -SPA (10-fold molar excess), for $1 \mathrm{~h}$. The solution was further mixed with EDC/Sufo-NHS for $30 \mathrm{~min}$ followed by reaction with the AT1 peptide (10-fold molar excess) for $4 \mathrm{~h}$. The AT1-HSA was purified by dialysis using the Slide-a-Lyzer dialysis cassette (10K Da MWCO). The purified sample was lyophilized and stored at $4{ }^{\circ} \mathrm{C}$.

\subsection{Nuclear Magnetic Resonance}

The 1D proton spectra were recorded at $25^{\circ}$ on a $500 \mathrm{MHz}$ Varian INOVA NMR Spectrometer, with an HCN triple resonance RT probe with Z-axis pulsed field gradients. Spectra were recorded with double pulsed-field gradient spin echo for suppression of residual $\mathrm{H}_{2} \mathrm{O}$ signal. Further, 256 scans with a recycle delay of $1 \mathrm{~s}$ were collected with a sweep width of $8000 \mathrm{~Hz}$ and an acquisition time of $1 \mathrm{~s}$. Data were processed with $1 \mathrm{~Hz}$ line broadening using the VNMRJ 4.2 software. The concentrations of HSA, AT1 peptide, and AT1-HSA were $5 \mathrm{mg} / \mathrm{mL}$ in $\mathrm{D}_{2} \mathrm{O}$. 


\subsection{Mass Spectrometry}

The AT1-HSA, AT1 peptide, and HSA samples were analyzed by the Matrix-Assisted Laser Desorption/Ionization Time of Flight Mass Spectrometry (MALDI-TOF-MS) MALDI Autoflex III- TOF-(BRUKER) SMARTBEAM) (Dept. of Chemistry, McGill University, Montreal, QC, Canada) in linear positive mode. Dihydroxybenzoic Acid was used as the Matrix and the AT1-HSA, HSA, and AT1 peptide samples were dissolved in water at concentrations of $7 \mathrm{mg} / \mathrm{mL}$

\subsection{Quantification of AT1 Peptide Attached to HSA}

The amount of AT1 peptide attached to the HSA molecule was determined by UVVisible spectrophotometry. Post surface modification of HSA with AT1 by chemical conjugation and prior to dialysis, the reaction mixture was centrifuged using Amicon centrifugal filters with 30 KDa MWCO. The unbound AT1 peptide (Mol. Wt. $1292 \mathrm{~g} / \mathrm{mol}$ ) was collected as the filtrate at the bottom of the tube and quantified by UV-Visible spectrophotometry at $280 \mathrm{~nm}$. A standard curve was prepared by making serial dilutions of AT1 to measure the unknown quantity of AT1 in solution.

\subsection{Nanoparticle Preparation}

The AT1-HSA-MRN-NPs were prepared by the ethanol desolvation technique $[35,36]$. Briefly, an aqueous solution AT1-HSA $(20 \mathrm{mg} / \mathrm{mL})$ was prepared in deionized water and solution $\mathrm{pH}$ was adjusted to $\mathrm{pH} 8.0$ using $0.1 \mathrm{M} \mathrm{NaOH}$. MRN was dissolved in DMSO and added to the AT1-HSA, with MRN/AT1-HSA (wt./wt.) at 1:10, 1:20, 1:40, and 1:80 [10]. Ethanol was added in a dropwise manner resulting in solution turbidity. Glutaraldehyde ( $8 \% v / v$ aq. solution) was added at a concentration of $0.588 \mu \mathrm{L} / \mathrm{mg}$ HSA and reacted for $24 \mathrm{~h}$. The nanoparticles were washed by three rounds of ultracentrifugation at $18,000 \times g$ for 15 min each at $25^{\circ} \mathrm{C}$. The supernatant was collected for detection of unbound MRN. The pellet was washed with deionized water and resuspended in PBS.

\subsection{Nanoparticle Characterization}

The average size of the nanoparticles was measured by Dynamic Light Scattering (DLS) using a Particle Size Analyzer (Brookhavens Instruments Corporation, Holtsville, NY, USA). The samples were diluted 1:20 with deionized water and measured at a scattering angle of $90^{\circ}$ and temperature of $25^{\circ} \mathrm{C}$. The Polydispersity Index (PDI) estimated the size distribution of the nanoparticles. The zeta potential was measured by a Zeta Potential Analyzer (Brookhavens Instruments Corporation, Holtsville, NY, USA) using electrophoretic laser Doppler anemometry. The size, shape, and surface morphology of the nanoparticles were examined by SEM and TEM techniques.

The yield of the nanoparticles was measured by the UV-spectrophotometric method $[9,10]$. A standard curve of HSA solution dissolved in Bradford reagent was used as a reference and absorbance was measured at $595 \mathrm{~nm}$. For measuring encapsulation efficiency, nanoparticles were spin concentrated using centrifugal filters (10K Da MWCO) for eluting the non-encapsulated MRN into the collection tube. The concentration of non-encapsulated MRN was determined by UV-spectrophotometry at $356 \mathrm{~nm}$. A standard curve of MRN in a DDQ/Ethanol mixture was used as reference [37].

\subsection{In Vivo Studies}

All experiments were performed on female Lewis Rats (200-250 g; Charles River Laboratories, Senneville, Quebec Canada) in accordance with the guidelines set forth by the Canadian Council on Animal Care and were approved by the institutional ethics committee. Rats were housed in groups of two to three per cage.

Two in vivo studies were performed. The first study includes pharmacokinetics and tissue distribution analyses on rats not having undergone the coronary artery ligation surgery. The second study evaluated the treatment efficacy of the targeted nanoparticle 
formulation in a rat model of CHF by performing ligation surgery of the left anterior descending (LAD) coronary artery.

\subsection{Pharmacokinetics and Biodistribution Study}

The animals were randomized into three groups in a blinded manner. Group I $(n=6)$ was intravenously injected with 1 c.c. saline. Group II $(n=12)$ was intravenously injected with $250 \mu \mathrm{L}$ of AT1-HSA-MRN-NPs containing $50 \mu \mathrm{g} / \mathrm{kg}$ MRN. Group III $(n=12)$ was intravenously injected with $250 \mu \mathrm{L}$ of MRN Lactate containing $50 \mu \mathrm{g} / \mathrm{kg}$ MRN. Blood was collected from the jugular vein at the following timepoints: $0,5,15,30,45,60,120$, and $360 \mathrm{~min}$. The animals were euthanized by isoflurane $/ \mathrm{CO}_{2}$. Organ tissues (heart, lungs, liver, and kidneys) were collected, washed, rinsed, and snap-frozen in liquid nitrogen.

\subsection{Ligation of the Left Anterior Descending Coronary Artery to Induce CHF}

The surgery was performed in a blinded manner as previously mentioned [22,38]. Briefly, rats were anesthetized using $5 \%$ isoflurane, intubated, and mechanically ventilated at 80 breaths/minute. Via a left thoracotomy (through the fourth intercostal space), the LAD coronary artery was permanently ligated $2 \mathrm{~mm}$ from its origin with a $7 / 0$ polypropylene suture (Ethicon Inc., Somerville, NJ, USA). The ischemic myocardial segment rapidly became identifiable through its pallor and akinesia corresponding to the distribution of the LAD coronary artery territory distal to the occlusion, which resulted in MI of the free left ventricle (LV) and subsequently heart failure. About $48 \mathrm{~h}$ after ligation of the artery, injections were performed using a $27-\mathrm{G}$ needle. Rats were randomized into five groups: Group $1(n=5)$ received an intravenous injection of 1 c.c. saline (Control). Group $2(n=8)$ received $250 \mu \mathrm{L}$ intravenous injection of AT1-HSA-MRN-NPs containing $50 \mu \mathrm{g} / \mathrm{kg}$ of milrinone. Group $3(n=8)$ received $250 \mu \mathrm{L}$ bolus intravenous injection of $50 \mu \mathrm{g} / \mathrm{kg}$ MRN Lactate [39,40]. Group $4(n=5)$ received $250 \mu \mathrm{L}$ intravenous injection of empty NPs in the same concentration as Group 1. Group $5(n=8)$ received $250 \mu \mathrm{L}$ subcutaneous injection of $50 \mu \mathrm{g} / \mathrm{kg}$ of AT1-HSA-MRN-NPs. The reason for using empty NPs as a control was to ensure that these particles had no effect on cardiac function or other inadvertent toxicity. Blood was collected $24 \mathrm{~h}$ post injection for milrinone quantification. Various endpoint measurements were taken as described in subsequent paragraphs. At 5 days post injection, all rats were killed by euthanasia. The hearts were washed with saline solution to remove excess blood and clots and then fixed in neutral-buffered $4 \%$ formalin.

\subsection{Animal Mortality}

Forty female Lewis rats were included in the study, with a total of thirty-four rats surviving till the 1-week experimental end point of the study. All mortalities occurred during surgery. There was no difference in mortality among the different groups. No mortality was observed in surviving rats.

\subsection{Blood Serum and Plasma Collection}

Blood was collected via the jugular vein from the animals using a sterile $23 \mathrm{G} / 25$ $\mathrm{mm}$ needle in the Microtainer®serum separator tubes (Becton Dickinson, Franklin Lakes, NJ, USA) for serum separation and in Plasma-EDTA tubes (Becton Dickinson, Franklin Lakes, NJ, USA) for plasma collection. The blood was allowed to clot at room temperature for $30 \mathrm{~min}$ and subsequently placed on ice until centrifugation. Serum was separated by low-speed centrifugation at $1500 \mathrm{rpm}$ for $15 \mathrm{~min}$ at $4{ }^{\circ} \mathrm{C}$ and was frozen at $-80^{\circ} \mathrm{C}$ until analysis. Serum was used to test for C-reactive protein (CRP) and liver function tests, alkaline phosphatase (ALP), alanine aminotransferase (ALT), and aspartate transaminase (AST). Urea, creatinine (CRE), and uric acid (UA) were also tested for renal functionality in the animals using a conventional enzymatic method on Hitachi 911 automated clinical chemistry auto-analyzer (Roche Diagnostics, Indianapolis, IN, USA). The plasma was separated by low-speed centrifugation at $2500 \mathrm{rpm}$ for $10 \mathrm{~min}$ at $4{ }^{\circ} \mathrm{C}$ and was frozen at 
$-80{ }^{\circ} \mathrm{C}$ until analysis. Plasma was used to detect milrinone levels using High Performance Liquid Chromatography (HPLC).

\subsection{Quantification of Milrinone from Rat Plasma}

The milrinone in plasma samples was quantified using High Performance Liquid Chromatography (HPLC) LCMS-8060 (Shimadzu). For sample preparation, stock solutions of milrinone $(1 \mathrm{mg} / \mathrm{mL})$ and amrinone $(1 \mathrm{mg} / \mathrm{mL})$ were prepared in DMSO. Amrinone was used as an internal standard. A working solution of amrinone at $250 \mathrm{ng} / \mathrm{mL}$ was prepared by serial dilution with deionized water. Further, $50 \mu \mathrm{L}$ of plasma was mixed with $10 \mu \mathrm{L}$ of internal standard and $500 \mu \mathrm{L}$ of ethyl acetate was added. The sample was vortexed and centrifuged at $15,000 \times g$ for $5 \mathrm{~min}$ and $400 \mu \mathrm{L}$ supernatant was separated. A standard curve was generated using rat plasma that was spiked with $1000 \mathrm{ng} / \mathrm{mL}$ milrinone and serially diluted. The standard curve samples were then spiked with $10 \mu \mathrm{L}$ of internal standard working solution $(0.25 \mathrm{ng} / \mathrm{mL}$ amrinone) and extracted with $500 \mu \mathrm{L}$ of ethyl acetate and $400 \mu \mathrm{L}$ of supernatant was dried. All samples were reconstituted in $40 \mu \mathrm{L}$ of mobile phase $A$ and analyzed by LC-MS/MS. Separation was performed on a reversed phase Kinetex XB $50 \mathrm{~mm} \times 2.1 \mathrm{~mm}$ column which was maintained at $40^{\circ} \mathrm{C}$. Samples were injected by loop overfilling into a $5 \mu \mathrm{L}$ loop. For the 6 min LC gradient, the mobile phase consisted of the following solvent $\mathrm{A}$ ( $5 \mathrm{mM}$ ammonium formate at $\mathrm{pH} 4.5$ in water) and solvent $\mathrm{B}(5 \mathrm{mM}$ ammonium formate in methanol) at a flow rate of $400 \mu \mathrm{L} / \mathrm{min}$. The gradient started at 95:5 A:B. Samples were quantified using the area under the curve (AUC) and a standard curve. Samples were integrated using the Browser extension from the Labsolution suite.

\subsection{Echocardiography Procedure}

Echocardiographic examinations were performed under inhaled isoflurane anesthesia ( $2.5 \%$ in oxygen, $500-700 \mathrm{~mL} / \mathrm{min}$ ). Transthoracic echocardiography was performed for each rat as a baseline before the surgery, $48 \mathrm{~h}$ post surgery, $60 \mathrm{~min}$ post injection, $24 \mathrm{~h}$ post injection, $48 \mathrm{~h}$ post injection, and 1-week post injection. Echocardiograms were obtained with a commercially available system (Micromaxx P04224; SonoSite, Bothell, WA, USA), equipped with a linear probe 7-13 MHz $25 \mathrm{~mm}$ footprint turbo transducer (P06519.11; SonoSite). Briefly, LV end-diastolic diameters (LVEDD) and end-systolic diameters (LVESD) were measured with $\mathrm{M}$-mode tracings between the anterior and posterior walls from the parasternal short-axis view just below the level of the papillary muscles of the mitral valve [13]. The time of end-diastole was defined as time of maximum diameter of the $\mathrm{LV}$ in one heart cycle. Accordingly, end-systole was defined as the minimum diameter. Following the American Society of Echocardiology leading-edge method, two images on average were obtained in each view and averaged over three consecutive cycles [41]. The left-ventricular end-diastolic volume (LVEDV) and left-ventricular end-systolic volume (LVESV) were measured using the Teichholz formula [13].

\subsection{Cytokine Measurement}

The cytokine analysis for levels of IL-6, IL-10, and tumor necrosis factor-alpha (TNF$\alpha$ ) was performed using commercially available ELISA kits (Abcam) according to the manufacturer's instructions. Microtiter plates were precoated with a murine monoclonal antibody against the rat cytokine being measured. Standards of the analyte and serum samples were added in triplicate. The absorbance was read at $450 \mathrm{~nm}$ within $30 \mathrm{~min}$ of stopping the reaction and standard curves were plotted.

\subsection{Tissue Collection and Histological Analysis}

After 1 week of treatment, the animals were anesthetized and sacrificed using pentobarbital sodium ( $100 \mathrm{mg} / \mathrm{kg}$ ) overdose. The heart, lungs, liver, and kidney were excised rapidly and washed with cold saline to remove excess blood and then fixed in neutralbuffered $10 \%$ formalin for $48 \mathrm{~h}$. The tissues were trimmed to $3 \mathrm{~mm}$ thickness and stored in $70 \%$ ethanol in histology cassettes. The tissues were paraffin-embedded and processed 
into 4-5 $\mu \mathrm{m}$ thick sections on slides (The Rosalind and Morrison Goodman Cancer Research Institute, McGill University). The tissue slides were stained with hematoxylin-eosin following manufacturer's instructions and observed by confocal microscopy at $400 \times$.

\section{Conclusions}

A novel nanoparticle formulation has been developed for targeted MRN delivery. The HSA was surface-modified to form AT1-HSA, which was used to develop the AT1HSA-MRN-NPs. As compared to the non-targeted MRN Lactate, the AT1-HSA-MRN-NPs exhibited prolonged drug release and superior pharmacokinetics and tissue distribution of MRN in vivo, improving cardiac function recovery with lesser toxicity and better proinflammatory/anti-inflammatory serum cytokine levels (IL-6, TNF- $\alpha$, and IL-10) in a rat model of congestive heart failure. Thus, this presents a new strategy of delivering hemodynamically stable drugs in a prolonged manner with a sustained release profile with negligible side effects. It also exhibits the feasibility and effectiveness of nanoparticle-based formulations in cardiovascular medicine. This novel nanoparticle formulation could be used as a potent, safe, and non-toxic heart failure medication, with potential for use in other cardiovascular diseases.

Author Contributions: Conceptualization, N.L.; methodology, N.L.; Z.K.S. and A.A.; software, N.L. validation, S.W., formal analysis, N.L.; investigation, N.L.; resources, D.S.-T. and S.P.; data curation, N.L.; writing—original draft preparation, N.L.; writing—review and editing, N.L. and S.W.; supervision, D.S.-T. and S.P.; project administration, D.S.-T.; funding acquisition, S.P. All authors have read and agreed to the published version of the manuscript.

Funding: This work is supported by the research funding granted to Satya Prakash from Canadian Institute of Health Research (CIHR PJT-166003) and the Natural Sciences and Engineering Research Council (NSERC). RGPIN-2019-06596.

Institutional Review Board Statement: All experiments were performed on female Lewis Rats (200-250 g; Charles River Laboratories, Senneville, Quebec Canada) in accordance with the guidelines set forth by the Canadian Council on Animal Care and were approved by the institutional ethics committee (approval No. AUP-7983).

Informed Consent Statement: Not applicable.

Data Availability Statement: The data presented in this study to support the findings are available within the study.

Acknowledgments: This work is supported by the research funding granted to Satya Prakash from Canadian Institute of Health Research (CIHR) and the Natural Sciences and Engineering Research Council (NSERC). The authors are grateful to Xue Dong Liu for assistance in TEM imaging (Facility for Electron Microscopy Research, Materials Engineering, McGill University), Tara Sprules and Nadim Saadeh for help with NMR and Mass Spectroscopy (Mass Spectroscopy Facility, Department of Chemistry, McGill University). The authors are also thankful to Aurore Dodelet-Devillers, Anna Choy, Annie Leblanc and Stephanie Lantosca at the Animal Resource Division, RI-MUHC, Montreal.

Conflicts of Interest: The authors declare no conflict of interest.

\section{References}

1. Benjamin, E.J.; Virani, S.S.; Callaway, C.W.; Chamberlain, A.M.; Chang, A.R.; Cheng, S.; Chiuve, S.E.; Cushman, M.; Delling, F.N.; Deo, R.; et al. Heart Disease and Stroke Statistics-2018 Update: A Report From the American Heart Association. Circulation 2018, 137, e67-e492. [CrossRef]

2. Benetis, R. Surgical treatment of congestive heart failure in coronary artery disease. Rocz. Akad. Med. w Bialymstoku (1995) $2005,50$.

3. Giardiello, M.; Liptrott, N.J.; McDonald, T.O.; Moss, D.; Siccardi, M.; Martin, P.; Smith, D.; Gurjar, R.; Rannard, S.P.; Owen, A. Accelerated oral nanomedicine discovery from miniaturized screening to clinical production exemplified by paediatric HIV nanotherapies. Nat. Commun. 2016, 7, 13184. [CrossRef] [PubMed]

4. Giménez, V.M.M.; Kassuha, D.E.; Manucha, W. Nanomedicine applied to cardiovascular diseases: Latest developments. Ther. Adv. Cardiovasc. Dis. 2017, 11, 133-142. [CrossRef] [PubMed] 
5. $\quad$ Ferreira, M.P.A.; Ranjan, S.; Kinnunen, S.; Correia, A.; Talman, V.; Mäkilä, E.; Barrios-Lopez, B.; Kemell, M.; Balasubramanian, V.; Salonen, J.; et al. Drug-Loaded Multifunctional Nanoparticles Targeted to the Endocardial Layer of the Injured Heart Modulate Hypertrophic Signaling. Small 2017, 13, 1701276. [CrossRef] [PubMed]

6. Chang, M.-Y.; Yang, Y.-J.; Chang, C.-H.; Tang, A.C.L.; Liao, W.-Y.; Cheng, F.-Y.; Yeh, C.-S.; Lai, J.J.; Stayton, P.S.; Hsieh, P.C.H. Functionalized nanoparticles provide early cardioprotection after acute myocardial infarction. J. Control. Release 2013, 170, 287-294. [CrossRef] [PubMed]

7. Diao, J.; Wang, H.; Chang, N.; Zhou, X.-H.; Zhu, X.; Wang, J.; Xiong, J.-W. PEG-PLA nanoparticles facilitate siRNA knockdown in adult zebrafish heart. Dev. Biol. 2015, 406, 196-202. [CrossRef]

8. Hennig, R.; Goepferich, A.; Pollinger, K.; Tessmar, J. Multivalent targeting of $\mathrm{AT}_{1}$ receptors with angiotensin II-functionalized nanoparticles. J. Drug Target. 2015, 23, 681-689. [CrossRef] [PubMed]

9. Lomis, N.; Westfall, S.; Farahdel, L.; Malhotra, M.; Shum-Tim, D.; Prakash, S. Human Serum Albumin Nanoparticles for Use in Cancer Drug Delivery: Process Optimization and In Vitro Characterization. Nanomaterials 2016, 6, 116. [CrossRef]

10. Lomis, N.; Gaudreault, F.; Malhotra, M.; Westfall, S.; Shum-Tim, D.; Prakash, S. Novel Milrinone Nanoformulation for Use in Cardiovascular Diseases: Preparation and in Vitro Characterization. Mol. Pharm. 2017, 15, 2489-2502. [CrossRef]

11. Mudshinge, S.R.; Deore, A.; Patil, S.; Bhalgat, C.M. Nanoparticles: Emerging carriers for drug delivery. Saudi Pharm. J. 2011, 19, 129-141. [CrossRef]

12. Blanco, E.; Shen, H.; Ferrari, M. Principles of nanoparticle design for overcoming biological barriers to drug delivery. Nat. Biotechnol. 2015, 33, 941-951. [CrossRef]

13. Binsalamah, Z.M.; Paul, A.; Khan, A.A.; Prakash, S.; Shum-Tim, D. Intramyocardial sustained delivery of placental growth factor using nanoparticles as a vehicle for delivery in the rat infarct model. Int. J. Nanomed. 2011, 6, 2667.

14. Paul, A.; Chen, G.; Khan, A.; Rao, V.T.S.; Shum-Tim, M.; Prakash, S. Genipin-Cross-Linked Microencapsulated Human Adipose Stem Cells Augment Transplant Retention Resulting in Attenuation of Chronically Infarcted Rat Heart Fibrosis and Cardiac Dysfunction. Cell Transplant. 2012, 21, 2735-2751. [CrossRef]

15. Loureiro, A.; Azoia, N.G.; Gomes, A.C.; Cavaco-Paulo, A. Albumin-Based Nanodevices as Drug Carriers. Curr. Pharm. Des. 2016, 22, 1371-1390. [CrossRef] [PubMed]

16. Dvir, T.; Bauer, M.; Schroeder, A.; Tsui, J.H.; Anderson, D.G.; Langer, R.; Liao, R.; Kohane, D.S. Nanoparticles Targeting the Infarcted Heart. Nano Lett. 2011, 11, 4411-4414. [CrossRef] [PubMed]

17. Paradis, P.; Dali-Youcef, N.; Paradis, F.W.; Thibault, G.; Nemer, M. Overexpression of angiotensin II type I receptor in cardiomyocytes induces cardiac hypertrophy and remodeling. Proc. Natl. Acad. Sci. USA 2000, 97, 931-936. [CrossRef] [PubMed]

18. Xu, J.; Carretero, O.A.; Lin, C.X.; Cavasin, M.A.; Shesely, E.G.; Yang, J.J.; Reudelhuber, T.L.; Yang, X.P. Role of cardiac overexpression of angiotensin II in the regulation of cardiac function and remodeling post-myocardial infarction. Am. J. Physiol. Heart Circ. Physiol. 2007, 293, H1900-H1907. [CrossRef] [PubMed]

19. Nakano, Y.; Matoba, T.; Tokutome, M.; Funamoto, D.; Katsuki, S.; Ikeda, G.; Nagaoka, K.; Ishikita, A.; Nakano, K.; Koga, J.-I.; et al. Nanoparticle-Mediated Delivery of Irbesartan Induces Cardioprotection from Myocardial Ischemia-Reperfusion Injury by Antagonizing Monocyte-Mediated Inflammation. Sci. Rep. 2016, 6, 29601. [CrossRef] [PubMed]

20. Liu, J.; Gu, C.; Cabigas, E.B.; Pendergrass, K.D.; Brown, M.E.; Luo, Y.; Davis, M.E. Functionalized dendrimer-based delivery of angiotensin type 1 receptor siRNA for preserving cardiac function following infarction. Biomaterials 2013, 34, 3729-3736. [CrossRef]

21. Al Kindi, H.; Paul, A.; You, Z.; Nepotchatykh, O.; Schwertani, A.; Prakash, S.; Shum-Tim, D. Sustained release of milrinone delivered via microparticles in a rodent model of myocardial infarction. J. Thorac. Cardiovasc. Surg. 2014, 148, 2316-2324. [CrossRef]

22. Lindsay, C.A.; Barton, P.; Lawless, S.; Kitchen, L.; Zorka, A.; Garcia, J.; Kouatli, A.; Giroir, B. Pharmacokinetics and pharmacodynamics of milrinone lactate in pediatric patients with septic shock. +288 . Pediatr. Res. 1996, 39, 50. [CrossRef]

23. Friedman, S.E.C.A.R.L.A.D.; Claypool, S.; Liu, R. The Smart Targeting of Nanoparticles. Curr. Pharm. Des. 2013, 19, 6315-6329. [CrossRef] [PubMed]

24. Chen, B.; He, X.Y.; Yi, X.Q.; Zhuo, R.X.; Cheng, S.X. Dual-Peptide-Functionalized Albumin-Based Nanoparticles with pHDependent Self-Assembly Behavior for Drug Delivery. ACS Appl. Mater. Interfaces 2015, 7, 15148-15153. [CrossRef] [PubMed]

25. Bobo, D.; Robinson, K.J.; Islam, J.; Thurecht, K.J.; Corrie, S.R. Nanoparticle-Based Medicines: A Review of FDA-Approved Materials and Clinical Trials to Date. Pharm. Res. 2016, 33, 2373-2387. [CrossRef]

26. Rivard, K.; Grandy, S.A.; Douillette, A.; Paradis, P.; Nemer, M.; Allen, B.G.; Fiset, C. Overexpression of type 1 angiotensin II receptors impairs excitation-contraction coupling in the mouse heart. Am. J. Physiol. Circ. Physiol. 2011, 301, H2018-H2027. [CrossRef]

27. Fasano, M.; Curry, S.; Terreno, E.; Galliano, M.; Fanali, G.; Narciso, P.; Notari, S.; Ascenzi, P. The extraordinary ligand binding properties of human serum albumin. IUBMB Life 2005, 57, 787-796. [CrossRef]

28. Merlot, A.M.; Kalinowski, D.S.; Richardson, D.R. Unraveling the mysteries of serum albumin-More than just a serum protein. Front. Physiol. 2014, 5, 299. [CrossRef]

29. Hirn, S.; Semmler-Behnke, M.; Schleh, C.; Wenk, A.; Lipka, J.; Schäffler, M.; Takenaka, S.; Möller, W.; Schmid, G.; Simon, U.; et al. Particle size-dependent and surface charge-dependent biodistribution of gold nanoparticles after intravenous administration. Eur. J. Pharm. Biopharm. 2011, 77, 407-416. [CrossRef] 
30. Suen, W.-L.L.; Chau, Y. Size-dependent internalisation of folate-decorated nanoparticles via the pathways of clathrin and caveolae-mediated endocytosis in ARPE-19 cells. J. Pharm. Pharmacol. 2014, 66, 564-573. [CrossRef]

31. Nanayakkara, S.; Byrne, M.; Mak, V.; Carter, K.; Dean, E.; Kaye, D.M. Extended-Release Oral Milrinone for the Treatment of Heart Failure with Preserved Ejection Fraction. J. Am. Heart Assoc. 2020, 9, e015026. [CrossRef]

32. Ayres, J.K.; Maani, C.V. Milrinone, in StatPearls. StatPearls Publishing. 2019. Available online: https://www.ncbi.nlm.nih.gov/ books/NBK532943/ (accessed on 1 July 2019).

33. Chong, L.Y.Z.; Satya, K.; Kim, B.; Berkowitz, R. Milrinone Dosing and a Culture of Caution in Clinical Practice. Cardiol. Rev. 2018, 26, 35-42. [CrossRef] [PubMed]

34. Langer, K.; Balthasar, S.; Vogel, V.; Dinauer, N.; von Briesen, H.; Schubert, D. Optimization of the preparation process for human serum albumin (HSA) nanoparticles. Int. J. Pharm. 2003, 257, 169-180. [CrossRef]

35. Langer, K.; Anhorn, M.G.; Steinhauser, I.; Dreis, S.; Celebi, D.; Schrickel, N.; Faust, S.; Vogel, V. Human serum albumin (HSA) nanoparticles: Reproducibility of preparation process and kinetics of enzymatic degradation. Int. J. Pharm. 2008, 347, 109-117. [CrossRef] [PubMed]

36. Siddiqui, M.R.; Tariq, A.; Ahmad, A.; Chaudhary, M.; Shrivastav, S.M.; Singh, R.K. Application of DDQ and p-Chloranilic Acid for the Spectrophotometric Estimation of Milrinone in Pharmaceutical Formulations. Asian J. Sci. Res. 2009, 2, 135-145. [CrossRef]

37. Abbasi, S.; Paul, A.; Shao, W.; Prakash, S. Cationic Albumin Nanoparticles for Enhanced Drug Delivery to Treat Breast Cancer: Preparation and In Vitro Assessment. J. Drug Deliv. 2012, 2012, 1-8. [CrossRef]

38. Drexler, H.; Höing, S.; Faude, F.; Wollschläger, H.; Just, H. Central and regional vascular hemodynamics following intravenous milrinone in the conscious rat: Comparison with dobutamine. J. Cardiovasc. Pharmacol. 1987, 9, 563-569. [CrossRef] [PubMed]

39. Huang, M.-H.; Wu, Y.; Nguyen, V.; Rastogi, S.; McConnell, B.K.; Wijaya, C.; Uretsky, B.F.; Poh, K.-K.; Tan, H.-C.; Fujise, K. Heart Protection by Combination Therapy with Esmolol and Milrinone at Late-Ischemia and Early Reperfusion. Cardiovasc. Drugs Ther. 2011, 25, 223-232. [CrossRef]

40. Davani, S.; Marandin, A.; Mersin, N.; Royer, B.; Kantelip, B.; Hervé, P.; Etievent, J.-P.; Kantelip, J.-P. Mesenchymal Progenitor Cells Differentiate into an Endothelial Phenotype, Enhance Vascular Density, and Improve Heart Function in a Rat Cellular Cardiomyoplasty Model. Circulation 2003, 108, II-253. [CrossRef]

41. Wykrzykowska, J.; Rosinberg, A.; Lee, S.U.; Voisine, P.; Wu, G.; Appelbaum, E.; Boodhwani, M.; Sellke, F.W.; Laham, R.J. Autologous Cardiomyotissue Implantation Promotes Myocardial Regeneration, Decreases Infarct Size, and Improves Left Ventricular Function. Circulation 2011, 123, 62-69. [CrossRef] 